\title{
LA NORMATIVA DEL CABILDO CATEDRAL DE SEGOVIA Y SUS DOCUMENTOS EN LA EDAD MEDIA
}

\author{
POR \\ DAVID ESPINAR GIL ${ }^{1}$ \\ Investigador independiente
}

\begin{abstract}
RESUMEN
Este trabajo ofrece un acercamiento a los estatutos y ordenanzas del cabildo catedral de Segovia entre los siglos XIII y XV. En un primer bloque se analizan cuestiones referentes al origen, significado y composición temática del régimen normativo, y en un segundo espacio se ofrece un estudio diplomático sobre los documentos que responden a esta tipología. El objetivo es dar a conocer la faceta normativa de las catedrales y su reflejo documental tomando el ejemplo de Segovia.
\end{abstract}

PALABRAS CLAVE: estatutos; documentos; cabildo catedral; Segovia; Edad Media.

\section{RULES OF THE CATHEDRAL CHAPTER OF SEGOVIA AND ITS DOCUMENTS IN THE MIDDLE AGES}

\begin{abstract}
This work offers an approach to the statutes and ordinances of the cathedral chapter of Segovia of the XIIIth and XVth centuries. In the first block there are analyzed questions regarding the origin, meaning and thematic composition of the normative regime, and in the second space a diplomatic study offers on the documents that they answer to this typology. The target is to announce the normative facet of the cathedrals and his documentary reflex taking the example of Segovia.
\end{abstract}

KEY WORDS: statutes; ordinances; documents; cathedral chapter; Segovia; Middle Age.

Cómo CITAR ESTE ARTículo / CITATION: Espinar Gil, David 2019. «La normativa del cabildo catedral de Segovia y sus documentos en la Edad Media». Hispania Sacra 71, 144: 399-416. https://doi.org/10.3989/hs.2019.028

Recibido/Received 16-09-2017

Aceptado/Accepted 21-02-2019

\section{INTRODUCCIÓN}

A lo largo de la Historia, pocas corporaciones han concentrado tantas manifestaciones culturales como los cabildos catedralicios hispanos. Aunque es probable que su origen esté vinculado a la práctica monacal de la Antigüedad tardía, su madurez institucional tuvo lugar durante los últimos siglos de la Edad Media. A partir de entonces, los cabildos protagonizaron un proceso de secularización en el cual abandonaron muchas de las prácticas regulares y desarrollaron nuevas funciones. ${ }^{2}$ Durante todo este proceso fue necesaria

\footnotetext{
1 d.espinargil@live.com / ORCID iD: https://orcid.org/0000-0002-0964-1838

2 Díaz Ibáñez 1998: 25-26. Para una relación más amplia y detallada
} de este proceso se puede consultar: Granado Hijelmo 2010: 38 y ss. la creación de una serie de disposiciones normativas que emanaron del propio cabildo, de su obispo diocesano o de ambos juntamente, según una distribución de competencias no exenta de discusiones. ${ }^{3}$ Su vigencia y aplicación fueron posibles gracias al reconocimiento de estos colectivos clericales como personalidades jurídicas de derecho. ${ }^{4}$ El proceso de articulación de estas normas se extiende por igual por los diversos centros capitulares, si bien aspectos como

3 La capacidad autonormativa se denomina potestas condendi statuta, y con la creación de leyes y normas se gestó el derecho capitular, entendido como ius singularis o iura propia. Este no es otra cosa que Derecho Común o ius comune (Derecho Romano y Derecho Canónico principalmente), del que procedía en buena medida. Pérez Martín 1999: 17-18.

4 Pérez-Prendes y Muñoz de Arraco 1997: 171-175. 
el modo de concesión, el contenido jurídico o el alcance de su aplicación, pueden resultar elementos característicos en las distintas sedes capitulares. Así, algunos cabildos recibieron sus estatutos de un modo agrupado, bien respondiendo a fervientes impulsos organizadores, ${ }^{5}$ bien por tratarse de cuerpos de reciente creación. ${ }^{6}$ Otros, atendiendo a necesidades puntuales, se dotaron de estatutos a lo largo de los siglos medievales de un modo paulatino. Alcanzado el siglo $\mathrm{XVI}$, la mayoría compilaba largas listas de textos normativos que sufrirían procesos de codificación, importantes reformas procedentes del papado en el contexto del Concilio de Trento y la injerencia de la monarquía, originando no pocos pleitos y debates. Después, los cabildos alcanzaron un estadio de solidez que ha perdurado hasta principios del siglo XX. ${ }^{7}$

Desde el punto de vista documental, toda esta actividad ordenativa generó unos tipos documentales denominados comúnmente estatutos, ordenanzas o constituciones, los cuales conforman espléndidos volúmenes de diversa condición diplomática conservados entre los ricos fondos de los archivos catedralicios. ${ }^{8}$ Existen algunos estudios destacados acerca de su contenido y alcance histórico-jurídico, pudiéndose citar el estudio del régimen estatutario de la catedral de Calahorra. ${ }^{9}$ También están presentes en el campo de las colecciones y ediciones documentales. ${ }^{10}$ No ocurre lo mismo en el ámbito diplomático donde, a pesar de contar con algunas referencias específicas, ${ }^{11}$ lo habitual es encontrarlos en estudios más amplios. ${ }^{12}$ Los trabajos sobre esta temática relativos a la catedral de Segovia siguen estas líneas historiográficas, encontrándose la edición de Villar García (que abarca buena parte de los documentos catedralicios anteriores a 1300), ${ }^{13}$ la transcripción de un estatuto del siglo XVI, facturada por Mariano Quintanilla, ${ }^{14}$ y los dos trabajos del profesor Martín Rodríguez en los que ofrece una aproximación analítica y edición de las ordenanzas de los capellanes de la catedral, y un aporte sobre los métodos contables y de gestión administrativa del cabildo reordenados en los años veinte del siglo XVI. ${ }^{15}$

5 En este sentido se puede citar el conjunto de constituciones que, en un contexto general de reordenación jurídico-administrativa y económica, el Cardenal Gil de Torres adjudicó a muchas catedrales hispanas a mediados del siglo XIII como Ávila, Salamanca, Burgos, Calahorra o Cuenca. Díaz Ibáñez 2003: 137-138.

6 Por ejemplo, el cabildo hispalense, que recibió la labor ordenativa del arzobispo Raimundo de Losaña (anteriormente obispo de Segovia): Costa Belda 1978. Así como también el cabildo catedral de Málaga, que recibió su corpus estatutario al poco de su conformación en 1492. García Mota 1993.

7 La esencia institucional de los cabildos catedrales se modificó sustancialmente tras la aprobación y publicación del Código de Derecho Canónico de 1917. Para profundizar en este asunto, consultar: Manzanares Marijuán 1993.

8 Se trata de uno de los principales grupos en los que grosso modo se pueden dividir los fondos capitulares, junto a otros como las actas capitulares y la documentación económica. Sobre esta cuestión, consultar: Lop Otín 2003: 383-384.

9 Granado Hijelmo 2010.

10 Valgan como ejemplo: Rodríguez Molina 1975; Luis López 2004a; Cotano Olivera 2009.

11 Chacón Gómez-Monedero 1996; Belmonte Fernández 2014.

12 Ostos Salcedo 1994; Riesco Terrero 1995; Marsilla Pascual 19951996; Ramos Merino 2012: 255-259.

13 Villar García 1990.

14 Quintanilla 1955.

15 Martín Rodríguez 1987, 1989.
Este trabajo estudia el conjunto de documentos normativos bajomedievales emanados de la catedral de Segovia, sede que cuenta con un importante volumen disperso y hasta cierto punto inédito. Un acervo que se custodia repartido en varias de las secciones del propio archivo catedralicio: las bandejas, donde se ubican pergaminos medievales y a la que se remite como "colección diplomática»; la sección de registros y documentos encuadernados, que se representa con las letras «C» y «D»; y, por último, las cajas, antiguos legajos sin demasiada coherencia archivística que contienen todo tipo de documentación. En este caso, solo se tendrá en cuenta la documentación emitida por el cabildo y por el obispo de Segovia. De este modo, primero se ofrece un bosquejo histórico de los principales estatutos y ordenanzas y, después, un estudio típicamente documental en el que se tratarán cuestiones relativas a la génesis, tradición y forma de los ejemplares. El objetivo es conocer en profundidad la documentación normativa de la sede segoviense utilizando los métodos de análisis propios de la disciplina Diplomática, sobre todo de sus especialidades episcopal y capitular. ${ }^{16}$ Se estima que ambas perspectivas se complementan mutuamente y ello permita una mejor comprensión de la temática. Con todo ello se espera contribuir al conocimiento del contexto histórico-documental, teniendo en cuenta la escasez de estudios diplomáticos sobre estatutos y ordenanzas capitulares y la importancia de estos como fuentes históricas. ${ }^{17}$

\section{EL RÉGIMEN NORMATIVO SEGOVIENSE: COMPOSICIÓN, TEMÁ- TICA Y ALCANCE INSTITUCIONAL}

Para comprender la esencia jurídica y documental de las normas por las que se rige un cabildo es necesario tener presentes los rasgos que lo caracterizan como típica institución eclesiástica. El cabildo es una corporación de clérigos cuyo origen se remonta al presbyterium o conjunto de personas que ayudan al obispo diocesano en el desempeño de sus funciones y asistían su casa episcopal. ${ }^{18}$ Desde los siglos XI y XII, los cabildos catedralicios actuaron como grupos adscritos a una iglesia mayor, cabeza de la diócesis y sede de la cátedra episcopal de lo cual toma el nombre de catedral. Como tal, estos colectivos se encargan de mantener el culto y solemnidad del templo, a la par que debían atender necesidades administrativas y de gestión. Además, desde este momento los cabildos fueron investidos de una personalidad jurídica propia distinta de la episcopal, factor de vital importancia que posibilitó su independencia y fortalecimiento institucional. Así, la catedral se erigió como gran templo litúrgico, receptor de donaciones pro anima y propietario de un rico patrimonio

16 La diplomática capitular es una especialidad que está en vías de desarrollo, si bien su autonomía y alcance historiográfico se viene defendiendo desde los últimos años gracias a la publicación de importantes trabajos. Vigil Montes 2012.

17 El conocimiento de estas fuentes resulta fundamental a la hora de abordar cualquier estudio sobre los cabildos catedrales y así ha quedado demostrado para los casos de Toledo o Ávila, por citar algunos ejemplos notables: Luis López 2004b; Lop Otín, María José. 2000. El Cabildo Catedralicio de Toledo en el siglo XV: aspectos institucionales y sociológicos. Tesis doctoral inédita, dirigida por Miguel Ángel Ladero Quesada. Universidad Complutense de Madrid, Facultad de Geografía e Historia.

18 Fliche y Martín 1976: 390. 
inmueble que le suponía voluminosas rentas; al mismo tiempo, acabó configurándose como centro de operaciones tanto eclesiásticas como civiles. ${ }^{19}$ El clero capitular se estructura en diversos grupos jerarquizados que suelen agruparse en tres categorías principales: dignidades, canónigos y racioneros. El de Segovia responde con creces a las características descritas y sus miembros desempeñaron diversos cometidos relacionados con el culto, la gestión económica, la caridad y otros que derivan de su facultad jurisdiccional, en tanto autoridad auxiliar del obispo y como ostentador de señoríos temporales. ${ }^{20}$ La evolución y el desarrollo de estas prácticas asociadas a la vida catedralicia constituyen hechos que van a quedar reflejados en los distintos tipos de normas publicadas para cada colectivo capitular. Entre ellas, se ha planteado la distinción entre preliminares, provisionales y específicas o eventuales. Algunos investigadores que se han acercado a la realidad institucional del cabildo de Segovia han identificado esta división y han interpretado que el grado de madurez del colectivo puede explicarse en función de la preponderancia de las normas generales sobre el resto. ${ }^{21}$ No hay que olvidar que las funciones reguladas por esta normativa, extendidas a dimensiones económicas, políticas y culturales, alcanzan a buena parte de los ámbitos y espacios de la sociedad, no solamente clerical. ${ }^{22}$ Esta asunción se hizo patente durante los siglos bajomedievales y el caso segoviense es un buen ejemplo de ello, ya demostrado por Miguel Santamaría Lancho en su estudio sobre el cabildo como unidad de extensión e influencia del poder político urbano. ${ }^{23}$

\subsection{El proceso de composición normativa}

Se desconoce el momento y el modo en que el cabildo catedral de Segovia maduró desde su primigenia formación conventual hacia una estructura jerárquica y multifuncional. ${ }^{24}$ La historiografía ha tomado como referencia la separación e independencia de las rentas entre el cabildo y el obispo, que se produjo a mediados del siglo XIII y dio lugar a las llamadas mesa capitular y episcopal. Para efectuar este proceso, el cabildo recibió una serie de cartas constitutivas de mano del legado pontificio Gil de Torres entre 1245 y $1250 .{ }^{25}$ En ellas se procede a la identificación, división y adjudicación de rentas entre obispo y cabildo, aprovechán-

19 Para una visión más amplia del esquema institucional, se puede consultar los trabajos: Sanz Sancho 2013 y Granado Hijelmo 2010.

20 Muchos de estos rasgos de los capítulos vinieron determinados por la aplicación a sus miembros de la noción romana de persona moral, a través de la cual se les concedió capacidad de disponer de propiedades, realizar contratos, administrar justicia o ejercer el derecho de asamblea. Fliche y Martín 1976: 390.

${ }_{21}$ Así lo indica Santamaría Lancho al describir la estructura funcional del cabildo según los parámetros que ofrece el esquema de estudio denominado como "Sociología de la Organización», utilizado para realizar su trabajo desde enfoques económico-administrativos. Santamaría Lancho 1982: 507-508.

22 Díaz lbáñez 1998: 30-32.

23 Santamaría Lancho 1990.

24 No hay que olvidar el posible pasado regular de los cabildos, aunque se piensa que el caso segoviano fue una excepción en este sentido. García Hernando 1970: 130.

25 Esta tipología documental cuenta con un trabajo donde se estudia desde el punto de vista jurídico-diplomático, tomando como ejemplo una constitución destinada a organizar la iglesia catedral de Salamanca: Riesco Terrero 1977. dose además para fijar percepciones pecuniarias y disponer ciertas normas de comportamiento. ${ }^{26} \mathrm{~A}$ juzgar por la documentación conservada y teniendo en cuenta que el peso de la costumbre es más que notable en esta clase de organizaciones, se cree que el cabildo no se dotó rápidamente de un corpus legislativo amplio. En su caso, inició un camino de articulación institucional a partir de las medidas del cardenal Gil de Torres, que se fue desarrollando ante la sucesión de determinadas cuestiones y necesidades. Ello explica un diverso y desigual desarrollo del cuerpo normativo hasta bien entrada la Edad Moderna. Aunque la cuestión está por estudiar, entre los fondos del archivo capitular se percibe una labor de ordenación normativa a mediados del siglo XVI y una codificación general de estatutos ya en el XVIII. ${ }^{27}$

¿Cuál era el procedimiento para establecer y recibir estas normas? Poco después de la intervención de Gil de Torres y, por tanto, de la adjudicación de las primeras disposiciones estatutarias, se ajustaron las primeras medidas normativas emanadas del cabildo y de su obispo diocesano. En ellas se certifica una estrecha colaboración entre ambas figuras que responde a una capacidad normativa compartida, con una especial preponderancia de la figura episcopal como cabeza de la diócesis y de su iglesia mayor. Como es bien sabido, el mecanismo episcopal para articular y gobernar el obispado fue la reunión periódica con su clero, es decir, los sínodos. La catedral formaba parte de la iglesia diocesana, pero dada la singularidad y marcada diferencia de su régimen estatutario, el trato de cuestiones referentes al clero capitular no fue habitual en los sínodos de la época. ${ }^{28}$ Sin embargo, para la diócesis de Segovia conviene hacer alguna observación. Hacia el año 1325, el obispo Pedro de Cuéllar celebró un importante sínodo $^{29}$ y en una de sus constituciones se delimitó el derecho capitular como porción del derecho canónico, ubicado este en un espacio intermedio entre la ley teológica y la civil, y caracterizado por tomar aspectos de ambas. ${ }^{30}$ Con esta mención, es probable que los capitulares

26 Estas medidas están relacionadas con el crecimiento de las rentas eclesiásticas acontecido durante el siglo XIII, y son consecuencia de la participación que tomó la monarquía en el aprovechamiento de las mismas a partir del reinado de Fernando III y la concesión de una porción del diezmo (Tercias Reales) que recibió del papa Inocencio IV. Además, no fueron pocas las iglesias envueltas en conflictos entre cabildos y prelados por el dominio de sus rentas. En este contexto se sucedieron numerosos procesos de control y regulación de rentas catedralicias y parroquiales, entre los cuales se ha de incluir el caso segoviano y la intervención de Gil de Torres, quien también actuó en otras muchas sedes con los mismos fines. Linehan 1975: 235-238.

27 Una buena parte de la documentación resultante de este proceso se halla agrupada en un voluminoso atado donde se ubican variadas ordenanzas, libros de regla y códigos específicos, bien originales, bien traslados, copias o memoriales, etc., y cuyo tejuelo indica de manera genérica: "Estatutos". Archivo Catedralicio de Segovia (en adelante ACS), D-1073-1088.

28 Granado Hijelmo 2010: 54.

29 Para ampliar contenidos sobre esta reunión, consultar: Martín y Linage Conde 1987.

30 Mas nos, que somos clérigos, que estamos en medio destos que husan mas de vida contemplativa (religiosos) e vida activa (abogados y jueces seglares), aviemos menester çiençia por la qual pudiesemos governar las cosas tenporales e spirituales, e por ende destas, de la theologia e de la çivil, que son leyes, que fallada la çiençia canonical, e por ende son dichos canonigos los de las iglesias cathedrales e colegiatas, porque se an de governar por esto. Sínodo de Pedro de Cuéllar, Libro Sinodal, Constitución 14. García y García 1993: 279. 
no solo quisieran perfilar su régimen normativo en el amplio abanico jurídico medieval, sino también manifestar su singularidad. ${ }^{31}$ Por aquellas fechas el cabildo no contaba con demasiadas disposiciones, pero la conservación de algunos registros de finales de siglo XIII, así como de libros de acuerdos desde el año 1321, permiten teorizar una organización funcional ya desarrollada.

Los primeros documentos normativos datan de 1258 y fueron otorgados simultáneamente por obispo y cabildo bajo el telón de un acto previo, el acuerdo. ${ }^{32}$ Este método fue el más habitual durante el período analizado. Así, la idea de independencia que puede desprenderse del episodio de la separación de rentas puede inducir a error al hacer pensar que el cabildo era responsable de su devenir institucional. La prerrogativa estatutaria solo le fue reconocida para sus asuntos internos, es decir, aquellos sobre los que el obispo no tenía jurisdicción. Sin embargo, la indefinición de algunos términos, así como la aparición de nuevas vicisitudes, dejó a la luz las carencias del sistema de reparto de competencias normativas. Esto dio lugar a conflictos que se dirimieron con avenencias o arbitrajes.

Los escenarios que suscitaban la creación de una norma capitular fueron, por tanto, diversos. Una primera vía parte de la propia voluntad del obispo. En este sentido, un precepto capitular puede tener su origen material en un decreto episcopal, como parece que ocurrió en 1303, año en que se fijó el pago del reverende. ${ }^{33}$ Sin embargo, la mayoría de las veces no existe un hecho previo de estas características y simplemente figura la conjunción de autoría entre obispo y cabildo, si bien con preponderancia del prelado. Así lo denotan expresiones anexas a la intitulación de los documentos y previas a su dispositivo en las que el obispo dice actuar: de consentimiento, e consejo e acuerdo del deán e cabildo ${ }^{34}$ o con consentimiento del dicho deán e cabildo. ${ }^{35}$ Esta aseveración lleva a otro rasgo imperante como lo fue el otorgamiento de ordenanzas y estatutos en las reuniones capitulares, de lo cual debía quedar constancia escrita en los libros de acuerdos al levantarse acta de la sesión. ${ }^{36}$ También en los documentos expedidos consta la reunión, mediante el uso de fórmulas de comparecencia incluidas en su exposición en las que, como se verá más adelante, se especifica que su convocatoria fue exclusiva para diseñar y publicar la normativa. Esto es lo que se deduce de frases incorporadas a la citada fórmula de comparecencia como: llamados espeçialmente para lo infraescripto. Otros casos permiten asumir que la creación estatutaria suponía un debate pro-

31 Conviene recordar que este sínodo se celebró con el objetivo de dar a conocer y aplicar los precedentes Concilio legatino de Valladolid (1322) y Concilio Provincia del Toledo (1324) en los que se trató la cuestión jurisdiccional y beneficial, entre otras muchas materias. Ibidem 260.

32 ACS, Colección Diplomática, 6-1, 6-2; Sanz Sanz 1988: 40; Villar García 1990: 275-280; Bartolomé Herrero 2003: 545-546.

33 El reverende es el nombre con que se conoce a la luctuosa en la época, es decir, un derecho que ostentaban los obispos y que «consistía en la entrega a éstos de determinados bienes de cada clérigo difunto y el disfrute de las rentas de los beneficios eclesiásticos hasta que fueran ocupados por el sucesor». Bartolomé Herrero 1998: 689.

34 ACS, Caja F-123.

35 ACS, Colección Diplomática, 15-14; Sanz Sanz 1988: 95.

36 Este proceso era común a una gran variedad de negocios y actos, y pertenece a la praxis documental de otros cabildos hispanos. Véase un análisis de la proyección documental de las reuniones capitulares en Vázquez Bertomeu 1997: 508 y ss. longado a lo largo de varios días, ya fuese en cabildo, como el estatuto de las heredades de $1383,{ }^{37}$ o fuera de él, según consta en las ordenanzas de Juan Ruiz de Medina del año 1504. ${ }^{38}$ Durante el siglo XV es frecuente encontrar estatutos y ordenanzas precedidas de un acto previo: la concordia. ${ }^{39}$ Esta podría darse bien entre obispo y cabildo, que fue lo más habitual, o entre alguna de las secciones del cabildo, y normalmente suelen referir a cuestiones relacionadas con la provisión de beneficios o al reparto de rentas. El acto quedaba fijado por escrito dando lugar a otra tipología documental similar en caracteres formales a los estatutos ordinarios. ${ }^{40}$ Cuando el clima no era tan afable y moderado, el asunto se dirimía mediante una sentencia arbitraria que era emitida por un juez árbitro elegido por las partes. En estos casos, también fue frecuente el otorgamiento de una escritura de concordia previa la cual, esta vez, disponía la elección de juez y el sometimiento de las partes a la sentencia pronunciada por este. ${ }^{41}$

A pesar de contar con estos datos de gran interés, no existen demasiadas noticias sobre el proceso de fondo necesario para la articulación normativa, salvo en ciertos casos. La voluntad de poner fin a un debate o remedio a una nueva situación obligaba a los miembros del cabildo a buscar antiguos preceptos o recopilar información procedente de otros ámbitos. Para ello, se comisionaba la labor de composición a personas concretas, y de ello ha quedado constancia en algunos documentos. Generalmente, eran dignidades o canónigos a los que a veces se sumaban letrados que los asistían en calidad de asesores. ${ }^{42}$ La búsqueda y consulta de documentos normativos custodiados en la catedral denota una valoración de situaciones previas. ${ }^{43}$ Este fue un modo habitual para atajar los debates existentes antes de proceder al diseño del estatuto en sí, y como tal constará en algunos expositivos documentales, tanto la presentación

37 (...) seyendo por ellos asignado cabildo para lo que adelante se sigue e otro sí lo que adelante se sigue seyendo por muchas vezes tratado por los dichos sennores del dicho cabildo por otros cabildos ACS, Colección Diplomática, 13-19.

38 (...) especial e espresamente ayuntados para faser e estatuyr e ortorgar lo infraescripto (...) el dicho sennor obispo dixo e propuso que bien sabían como en días pasados le abía sido por ellos fecha rrelaçión que en esta su iglesia avía diversos estatutos et ordenanças algunas dellos fechos por los obispos antepasados (...). ACS, D-1072, Estatuto de Juan Ruiz de Medina, fo. 1v.

39 Mecanismo frecuente entras diócesis como Cuenca. Díaz Ibáñez 2003: 139 y 142.

40 Se puede citar la que firmaron el obispo Luis de Acuña y el cabildo catedralicio en 1456 sobre el aprovechamiento de unos dominios y, al mismo tiempo, en relación al uso de los turnos para la provisión de vacantes, lo cual en conjunto tendrá valor de estatuto tras la aprobación del texto en sesión capitular, ACS, Caja F-29. También otra concordia a la que llegaron en 1465 el obispo Juan Arias Dávila y el cabildo aclaró, de nuevo, aspectos del sistema de turnos, que daría lugar al estatuto fechado en el mismo día. ACS, Caja H-88.

41 Por ejemplo, la sentencia arbitraria sobre el traer de los bonetes precedida de la preceptiva concordia, dada en 1456. ACS D-1072, fols. $68 \mathrm{r} 72 \mathrm{v}$.

42 Valga como ejemplo la comisión que el cabildo emitió en la sesión del 16 de septiembre de 1496 sobre el arcediano de Segovia y dos canónigos para diseñar un estatuto que regulase las estancias de estudiantes, en cuya labor serían asesorados por letrados del cabildo. ACS, Registro de Acuerdos Capitulares, C5, fo. 128r.

43 Este fenómeno se identifica, por ejemplo, en los estatutos de 1289 y 1339 . ACS, Colección Diplomática, 8-15 y 12-8; Sanz Sanz 1988: 76; Villar García 1990: 343-345; Bartolomé Herrero 2003: 658. 
de los documentos como los análisis efectuados sobre los mismos. ${ }^{44}$ Las concordias también fueron traídas a colación como precedente, y podían ser incorporadas a ordenanzas posteriores como ocurre en el estatuto de las exequias de 1500. Una de sus disposiciones hace alusión a la concordia que hubo entre el cabildo y el obispo Juan Arias Dávila sobre los derechos del reverende. Según el tenor de la nota, esta concordia fue incluida por su íntima relación con el tema principal del estatuto que se estaba componiendo, evitando además la pérdida o extravío que podía causar su consulta eventual. ${ }^{45} \mathrm{~A}$ veces la cuestión a reglamentar carecía de precedentes o suponía una novedad. En estos casos el cabildo pidió referencias a otras sedes. Ocurre esto con un estatuto sobre los sobornos que se trajo de la catedral de Toledo para incorporarlo al conjunto normativo segoviense hacia $1502 .{ }^{46}$ Para completar esta visión cabe citarse aquellos preceptos cuyo origen se encuentra en la costumbre, fuente normativa de gran rigor en la institución catedralicia. Una situación que se puede ejemplificar a través del propio estatuto de las exequias y misas de difuntos del año 1500, en cuyo tenor expositivo se deja constancia del paso de la norma costumbrista a la norma escrita. ${ }^{47}$

Por último, cabe mencionar formas y métodos de apuntalar el régimen normativo, entre las que hay que destacar la confirmación. Lo habitual es encontrar el acto escuetamente plasmado en los libros de acuerdos capitulares, sin mayor consecuencia documental. Bien es cierto que el propio juramento que debían hacer los prelados en el momento de su investidura puede considerarse, a efectos prácticos, una confirmación episcopal. Además de ello, existen cartas facturadas expresamente con este fin, como la del obispo Benito Pérez de 1319 que confirma ciertas disposiciones de sus antecesores y algunas del cardenal Gil de

44 Por ejemplo en la concordia entre Luis de Acuña y el cabildo de 1456 se dice: mostraron e presentaron a su sennoría ciertas escripturas instrumentos, colaçiones, privilegios, estatutos (...) los dichos sennores del cabildo e de su común consentimiento avía cometido e cometió e mandado e mandó al dicho sennor don Alfonso, canónigo, que supiesen e pesquisasen dellos la verdad e de cada uno dellos por escripturas e provanças e libros e testigos o por mejor manera que pudiesen e después en estos mesemos e en los otros negocios restantes infrascriptos (...) fallava e falló (el deán) según de las dichas escripturas e porvanças pertenesçer la colación dellas a él e a los dichos deán e cabildo en esta guisa... ACS, Caja F-29, fols.1r-1v.

45 Otrosi, por quanto en una concordia e asiento quel señor don Iohan Arias de Ávila (...) fiso e asentó con los señores deán e cabildo desta yglesia (...) e non se puede cada vegada buscar e sacar el dicho estatuto e concordia acordaron los dichos señores que fuese aquí puesto porque cada uno tenga dello notiçia. Ibídem., fo. 3r. Esto ilustra cómo el manejo de documentos también fue algo frecuente en la composición de nuevos instrumentos capitulares, como ya ocurrió con los estatutos de 1289 y 1339.

46 ACS, Caja F-21. Este ejemplar también consta en el libro compilatorio de estatutos y constituciones de la catedral de Segovia de 1563, en el que aparece el siguiente encabezado: Ay un estatuto que mandó el cabildo traer de Toledo sobre los sobornos el qual dize ansi. ACS, D-1072B, fols. $133 r-134 r$.

47 (...) que por quanto la memoria de los onbres es flaca e por antigüedad e largura del tiempo vienen las cosas en olvidança, que era cosa conveniente de poner en escripto las costumbres que los dichos señores tienen e los derechos que han de aver en los enterramientos e obsequias que se fasen quando algunos señores fallesçen, así dignidades como canónigos e rraçioneros e medio rraçioneros, para que los presentes no lo olviden y los venideros lo fallen en escripto. ACS, D-1073-1088, núm 10 , fo. $1 r$.
Torres. ${ }^{48}$ Otras, como la confirmación de la redistribución de las tercias annatas hecha por el cabildo y el obispo Juan de Cervantes en forma de estatuto en el año 1453, precisó de la intervención de una autoridad externa al capítulo. Es el caso del abad del monasterio de Santa María de los Huertos de Segovia, comisionado del papa Nicolás V, que intitula la bula de confirmación mediante la cual se renovó la efectividad de esta disposición. ${ }^{49}$

\subsection{Aspectos regulados: breve revisión temática}

¿Qué aspectos regulan los estatutos capitulares? Como se ha dicho, los primeros documentos normativos fueron publicados en 1258 y, en buena medida, su contenido viene a consolidar la labor del cardenal Gil de Torres, pues aclaran algunos de sus términos. Estos tenían que ver con la distribución de las rentas del diezmo que conforman las dotaciones básicas y suplementarias que habrían de percibir los capitulares en función de su rango, entre otras atribuciones..$^{50}$ Más tarde, en 1289, el obispo Blasco Rodríguez en conjunto con el propio cabildo, recordó la observancia de algunos preceptos ordenados, tanto por el cardenal como por otros obispos predecesores, además de fijar nuevas disposiciones. En esencia se trataba de cuestiones orgánicas y económicas, aunque también hubo espacio para establecer la celebración de costumbres tal que comidas o colaciones entre obispo y cabildo. ${ }^{51}$

Fue durante el siglo XIV cuando el cabildo, con la intervención de su prelado la mayoría de las veces, comenzó a publicar normas de diferente temática. La historiografía contempla la opción de que la institución había alcanzado su madurez formal a mediados de esta centuria. ${ }^{52}$ Entre los preceptos, en primer lugar, destacan los que versan sobre cuestiones plenamente jurisdiccionales, de vital importancia puesto que a través de ellos se rige el funcionamiento institucional del cabildo. Por ejemplo, el estatuto otorgado por el obispo Pedro de Cuéllar en 1339 en el que se estipulan los derechos y capacidades del deán para dirigir el cabildo y el coro, algo que fue discutido en varios momentos de la Baja Edad Media. ${ }^{53}$ En 1350 se publica otro de similar calado que establece quién ostenta la facultad de convocar cabildo en caso de ausencia del deán. ${ }^{54}$ Esta línea normativa también engloba a aquellos preceptos cuya razón de ser estriba en el deseo de cuidar el decoro y la seguridad en la catedral, que son de contenido penal y, por tanto, jurisdiccional. Es el caso del estatuto aprobado en 1311 contra los que cometiesen delitos de injuria, ${ }^{55} \mathrm{u}$ otro que se castigó en

48 ACS, Colección Diplomática, 11-6; Sanz Sanz 1988: 70; Bartolomé Herrero 2003: 629.

49 ACS, Colección Diplomática, 16-8-bis; Sanz Sanz 1988: 102.

50 El desglose completo de esta repartición en Santamaría Lancho 1983: 684-690.

51 ACS, Colección Diplomática, 8-15; Sanz Sanz 1988: 53-54; Villar García 1990: 343-345; Bartolomé Herrero 2003: 520.

52 Santamaría Lancho 1990: 52 y 70.

53 ACS, Colección Diplomática, 12-8; Sanz Sanz 1988: 76, Bartolomé Herrero 2003: 658.

54 ACS, Colección Diplomática, 12-15; Sanz Sanz 1988: 77: Bartolomé Herrero 2003: 668.

55 ACS, Colección Diplomática, 10-17; Sanz Sanz 1988: 67; Bartolomé Herrero 2003: 620. 
1440 las molestias y perturbaciones que pudieran sufrir los capitulares. ${ }^{56}$

En el siglo XV el cabildo perdió parte de su capacidad para disponer vacantes beneficiales a causa de la injerencia real, pontificia, e incluso episcopal. Este hecho motivó la fijación de nuevas normas que regulasen el acceso a las prebendas catedralicias. Cuestión que resultaba de todo punto delicada, teniendo en cuenta el papel del cabildo como mecanismo de influencia y de ascenso social, así como las fuertes rivalidades familiares de la ciudad. ${ }^{57}$ Sobre esta cuestión existen cartas normativas ya desde 1384, como la que permite la obtención de beneficios fuera de la diócesis. ${ }^{58}$ En el cuatrocientos, las concordias y estatutos abordaron directamente la provisión de beneficios capitulares estableciendo un meticuloso sistema de turnos, concretamente en los años 1453 y $1465 .^{59}$

A la provisión beneficial fue asociada una retención de dinero cuyo destino y cuantía fluctuó durante esta centuria; se entra de lleno en el terreno económico. Así, se ordenó un estatuto en 1402 para fijar un pago por las provisiones que se destinó al mantenimiento de ornamentos de la catedral, ${ }^{60}$ y otros dos otorgados en 1436 donde se estableció el pago de distintas cantidades de plata con arreglo a la colación de los cargos y oficiales del cabildo. ${ }^{61}$ Siguiendo con asuntos de índole económica, en 1383, el cabildo, esta vez en solitario, vio necesaria la defensa de las propiedades de su mesa y ordenó que los capitulares tomasen censos sobre las heredades, pues muchas se hallaban malparadas. ${ }^{62} \mathrm{Ya}$ en la centuria siguiente, en 1443 , se estableció por medio de otra carta la extracción de una cantidad equivalente a dos prebendas desde las mayordomías de Pitanzas y Común para el mantenimiento del patrimonio inmobiliario. ${ }^{63}$ De fecha indeterminada es el llamado "estatuto de las rentas» compuesto probablemente en el siglo XIV para ordenar las actividades de arrendamiento generadas para la explotación las rentas decimales del cabildo. ${ }^{64}$

Finalmente, otros estatutos recogen aspectos litúrgicos, así como los períodos vacacionales, las fiestas, el vestuario, o la profesión de caridad y asistencia a enfermos. Si bien es cierto, gran parte de ellos no llegaron a extenderse en un documento definitivo, sino que se asentaron únicamente en los libros de acuerdos capitulares. Entre los documentos emitidos por el cabildo destaca, por su solemnidad diplomática, la ordenanza que regula la actividad y sustento económico de los niños del coro y de su maestro de canto, que

\footnotetext{
56 ACS, Caja L-102. El contenido de este estatuto alcanza también al resto de clérigos del obispado.

57 Santamaría Lancho 1990: 50.

58 ACS, Colección Diplomática, 14-7; Sanz Sanz 1988: 86; Bartolomé Herrero 2003: 740.

59 ACS, Caja H-89 y Caja H-88. Sistema de turnos presente en otras sedes, como Burgos, con ciertos matices por ser esta diócesis exenta de toda jurisdicción metropolitana. Guijarro González 2008: 288-293.

60 ACS, Colección Diplomática, 15-2; Sanz Sanz 1988: 90.

61 ACS, Colección Diplomática, 15-13 y 15-14; Sanz Sanz 1988:

62 ACS, Colección Diplomática, 13-19; Sanz Sanz 1988: 85-86; Bartolomé Herrero 2003: 740.

63 ACS, Caja L-103.

64 Las menciones a este estatuto son constantes en la serie denominada "Libros de Rentas», cuadernos donde se asentaban las subastas y remates de estas rentas.
} 94-95. fue publicada en 1466 y que actualmente se conserva en el Archivo Diocesano. ${ }^{65}$

\subsection{El alcance institucional de la norma: juramento y lectura de estatutos capitulares}

Tanto el obispo como el cuerpo clerical catedralicio debían jurar el conjunto de estatutos y ordenanzas en el momento de su nombramiento o provisión de beneficio. Este acto se solía recoger por escrito en los libros de acuerdos del cabildo, pues tenía lugar en sesión plenaria, pero también puede dar lugar a documentos extendidos en forma pública. En este sentido puede citarse, por ejemplo, la recepción de Fernando López de Villaescusa como obispo en $1457 .{ }^{66}$ El formulario del documento se asemeja al de un acta notarial con un expositivo que recoge la instancia del cabildo al obispo para que efectúe el juramento ${ }^{67}$ y, a continuación, recoge un listado de estatutos o memorial que el obispo debía asumir bajo juramento después de ser presentados y leídos los originales. Según consta, el uso del memorial ya estaba extendido a mediados del siglo XV. ${ }^{68}$ Por su parte, los miembros del cabildo debían hacer lo propio cuando accedían a su cargo, momento en el que tenía lugar en un acto de provisión beneficial conocido como colación. Existen varios testimonios escritos que atestiguan este acto y la jura de los estatutos. Por un lado, las actas capitulares, donde quedan registradas las colaciones de beneficios capitulares de un modo resumido $y$, por ende, haciendo escuetas referencias al juramento. ${ }^{69}$ Por otro lado y gracias a la conservación de listas de estatutos en otros formatos, se puede comprobar que el acto debía ser muy similar al que efectuaban los obispos en su ceremonia de recepción, con la única salvedad de que debían jurar honra y respeto al prelado y a su mesa episcopal. Esta información aparece, por ejemplo, en la contraportada apergaminada de uno de los libros de actas capitulares, concretamente el de los años 1503 a 1506, donde se ubica el mencionado listado de preceptos a jurar bajo el título Juramento que han de faser qualquier señor quando es admitido a la posesión de prebenda o dignidad e etcétera. ${ }^{70}$

Aunque se desconoce el origen del juramento, se piensa que el acto puede retrotraerse al menos al siglo XIII. El estatuto compuesto por el prelado Blasco Rodríguez y el cabildo

\footnotetext{
65 Archivo Diocesano de Segovia (ADS), legajo 2058.

66 ACS, Caja L-102.

67 E luego los dichos sennores deán e cabildo dixieron e rrogaron e pidieron e rrequirieron al dicho sennor obispo que jurase su merçed los estatutos e ordenanças e buenas costunbres de la dicha iglesia según e por la manera e forma que los sus antecesores avían jurado e guardado ansí en espeçial como en general (...). Ibidem, fo. 1r.

68 (...) e en espeçial un escripto de memorial de estatutos que ende le fue mostrado e leydos, teniendo presentes los estatutos originales de que en el dicho escripto de capítulos se face mención e de cada uno dellos, su thenor del qual dicho escripto e memorial de los dichos capítulos de verbo ad verbum es este que se sigue. Idem.

69 Por ejemplo, la recepción de Antón Monte como canónigo de la cual consta en el registro: E luego el dicho Antón Monte fiso juramento en ánima del dicho licenciado de guardar los estatutos e ordenaçiones e costunbres en provecho e onrra al cabildo e sennores e rreverençia al sennor obispo. ACS, Registro de acuerdos capitulares, C2, fol. 2 r (2 de octubre de 1454).

70 ACS, Registro de acuerdos capitulares, C8 (1503-1506), segunda contraportada.
} 
en 1289 contiene la primera mención escrita sobre su modo de proceder. ${ }^{71}$ Según dispone, cada obispo debía prestar juramento corporal sobre los estatutos hechos por el cardenal Gil de Torres, así también los canónigos y racioneros del cabildo. ${ }^{72}$ Con probabilidad, el procedimiento se mantuvo con el paso del tiempo añadiéndose a la lista de textos jurados los nuevos preceptos que fueron aprobados posteriormente, tal como reflejan los testimonios de la decimoquinta centuria.

Para asegurar el cumplimiento de los estatutos previamente jurados se practicó la lectura pública de los mismos. Esta actividad puede enraizarse con las lecturas de tradición monástica de diferentes textos y obras litúrgico-filosóficas que, sin duda, se practicaron en el seno de las catedrales desde sus orígenes. En Segovia, la primera referencia acerca de la obligación de leer anualmente ordenanzas está dispuesta en el estatuto de Pedro de Cuéllar de 1339, y se fundamenta en la ignorancia que manifestaban algunos capitulares. ${ }^{73}$ Gracias a testimonios escritos posteriormente sobre los documentos originales, se constata un cierto cumplimiento de esta disposición que, en ocasiones, tuvo lugar fuera del cabildo, probablemente por alguna circunstancia extraordinaria. En la espalda del pergamino que contiene el estatuto de 1311, que penaliza las injurias y otras faltas ético-morales, figuran un testimonio de lectura en cabildo del año 1351 y otro de presentación y lectura en la villa de Sepúlveda en $1436 .^{74}$ Los libros de acuerdos también han dejado noticias de un cierto cumplimiento de la obligación de lectura anual en la fecha estipulada, aunque no se pueda confirmar su práctica de manera rotunda para todo el período estudiado. ${ }^{75} \mathrm{~A}$ juzgar por las descripciones presentes en las actas, todo indica que los documentos originales eran llevados físicamente al cabildo para proceder a su lectura. ${ }^{76}$ Este tipo de usos y prácticas pudo ser motivo más que suficiente como para plantear en cierto momento la copia seriada de cada uno de ellos, dando lugar a códices manuscritos compilatorios que se verán más adelante.

71 Agradezco a Bonifacio Bartolomé Herrero la aportación de este dato.

72 Primo que episcopus in consecratione sua vel quam cito ad iuerit ecclesiam de servanda ordinatoremm domini Egidii cardinalis, de mandato apostolice sedis facta, presete corporaliter iuramentum. Idem et faciant in sua introductione omnes alii socii mansionarii sive sint portionarii sive canonici vel persone. ACS, Colección Diplomática, 8-15.

${ }^{73}$... y porque muchos alegan ignorançia que disen que no saben las constituçiones de la eglesia, porque de aquí adelante no puedan alegar ignorançia, ordenamos e mandamos que de aquí adelante cada año sean leídas e publicadas una vegada en el año por cabildo universal todas las ordenaçiones de la nuestra eglesia, e tanbién las del cardenal don Gil, como todas las otras de los nuestros anteçesores. E el dia que se publiquen ordenamos cabildo para siempre el primer día que oviere aniversarios, después del domingo de quasimodo. ACS, Colección Diplomática, 12-8.

${ }_{74}$ Esta carta fue leyda estando ayuntados el deán e cabildo, lunes siete días de enero, era de mil e ccclxxxvi años. Antón Sanches. Presentado en Sepúlveda antel bachiller Juan Serrano, juez comisario del dicho sennor rrey, sábado XXII días de junio de mil e quatroçientos e treynta e seis años... ACS, Colección Diplomática, 10-17 (vuelto).

75 ... leyéronse en el dicho cabildo muchos de los estatutos de la dicha yglesia como es de costumbre de se leer e publicar en tal día como oy e etc. Testigos... ACS, Registro de acuerdos capitulares C4, fo..181v (1477, abril, 14)

76 ...el lugarteniente de deán traxo los estatutos para los leer e publicar e se enpeçaron a leer e dieronlos por leydos e etc. ACS, Registro de acuerdos capitulares C3, fo. 18v (1474, abril, 18).

\section{LOS DOCUMENTOS NORMATIVOS: ACERCAMIENTO DIPLOMÁTICO}

Hasta este punto se ha hecho una valoración de los procedimientos de articulación normativa ejecutados por el cabildo catedral de Segovia, se ha ofrecido una breve revisión de los aspectos regulados y se han identificado actos de asimilación institucional con vistas a garantizar su cumplimiento. En este capítulo se va a analizar la producción escrita que desarrolló el cabildo para salvaguarda y defensa de su régimen estatutario. Los estatutos capitulares son documentos de carácter disciplinar o reglamentista, de tipo acta, tal como se extrae de la clasificación articulada por el Dr. Ángel Riesco, junto a otros de orden interno, reguladores de derechos y obligaciones como fueros, constituciones $u$ ordenanzas. ${ }^{77}$ Recurriendo a la clasificación tipológica planteada por el profesor Francisco Marsilla, los estatutos catedralicios se ubican dentro de la documentación capitular administrativa, gozando de una entidad propia que los sitúa a la par de otras cartas y documentos. ${ }^{78}$ Ahondando algo más en sus consideraciones, los estatutos corresponderían con lo que él denomina "documentos de primer grado", ya que se trata de instrumentos emitidos, generalmente, en forma pública, y en cuya elaboración existe una intervención directa del deán y cabildo, además de la del obispo. ${ }^{79}$ Los estatutos capitulares procedentes de la catedral de Segovia encajan bien en ambas clasificaciones que se pueden considerar no excluyentes. Los tipos documentales localizados se definen en la propia formulación como statuta (estatuto) $\mathrm{u}$ ordinationis cartam (carta de ordenamiento) cuyo verbo dispositivo es statuo (establecer, fijar, disponer) conjugado en la primera persona del plural, statuimus, para los documentos latinos, y ordenamos, establesçemos o estatuimos, para los castellanos. Por tanto, se trata de documentos de tipo dispositivo que, como se verá, gozan de unas características diplomáticas concretas.

\subsection{La génesis documental}

La génesis documental estudia las distintas etapas por las que pasa un documento desde la voluntad de las partes hasta su concreción y entrega material. En la hechura documental participan tres personas: el autor, el destinatario y el rogatario. Para la ocasión, estas figuras corresponden con el cabildo y el obispo (autores), el cabildo propiamente dicho, o parte de él, como destinatario, y con los notarios eclesiásticos que van a hacer las veces de rogatarios, especialmente a partir de finales del siglo XIV. Esta división personal resulta oportuna para diferenciar las dos fases principales que conforman la génesis del documento: la actio y la conscriptio. En la primera, toman parte los autores y destinatarios, mientras que durante la segunda el protagonismo recae sobre el notario, principalmente. ${ }^{80}$ El estatuto u ordenanza constituye en sí mismo un acto jurídico que, normalmente, da lugar a varios testimonios escritos, como ocurría con buena parte de los asuntos tratados por un cabildo. De este modo, unos actos normativos quedaron registrados como

\footnotetext{
77 Riesco Terrero 1995: 402-403.

78 Marsilla Pascual 1995-1996: 166.

79 Ibídem: 155.

80 Se sigue la concepción y desglose de la génesis documental estipulada en: Marín Martínez 1991, Tomo 2: 164-170.
} 
notas sencillas en los libros de acuerdos, encabezadas por medio de imperativos como mandaron, ordenaron, etc., mientras que otros fueron extendidos como documentos en pública forma por ruego del deán y cabildo, y de su obispo, constando también su notación en los registros. Se entiende que la diferencia entre ambos estriba en la existencia o no de esta iussio o mandato documental, de tal manera que algunos estatutos u ordenanzas no motivaron su extensión en documento, mientras que otros sí. ${ }^{81}$ Conviene recordar que este mandato sí existe para formalizar por escrito el asiento del acta correspondiente en el libro registro, y que es dirigido al secretario capitular.

\section{La actio}

Como se vio en la explicación del proceso de composición, el diseño de los preceptos normativos tiene origen en la decisión colegiada del cabildo, en la que, como se dijo, la figura episcopal es partícipe en aquellos asuntos cuya competencia comparte con la corporación catedralicia. No se tienen excesivas noticias de la fase de petitio de estos documentos, aunque se entiende que el cabildo iniciaría el acto con el reconocimiento expreso de la necesidad de ordenar o estatuir un asunto, de lo cual sí ha quedado reflejo en la exposición de motivos. La interventio o consentio ha de comprenderse como el acuerdo común alcanzado por la corporación para proceder con el acto y se manifiesta en el tenor cada vez que se incorporan expresiones del tipo de consentimiento, e consejo e acuerdo. Del mismo modo, existe noticia de no consentio en una reunión del 15 de octubre de 1476 en la que se debatió la regulación de la tenencia de mulas $y$, ante lo dispuesto, los medio racioneros no consistieron su aprobación. ${ }^{82}$ La testificatio es otra de las fases de la actio declaradas expresamente en los documentos estatutarios. Es frecuente encontrar referencias a la presencia de testigos tanto al principio del texto (ante los testigos yuso escriptos) como al final (Testigos que fueron presentes a todo lo que dicho es), incluso a veces añadiéndose la fórmula de ruego y pedimiento que acompaña a los actores del documento.

\section{La conscriptio}

Gracias a la conservación de libros registro de acuerdos capitulares, documentos originales y algunos de sus borradores, se puede decir que son notables las noticias existentes sobre las distintas fases de la puesta por escrito de documentos normativos definitivos. La suscripción notarial, presente en todos los documentos y en algún borrador, constituye una buena aportación para la identificación de la iussio-rogatio o mandato de escrituración. En este apartado la iussio se atestigua mediante la expresión: por mandado, pero es más frecuentemente el ruego mediante fórmulas como a ruego $e$ pedimiento o rruego e otorgamiento (del cabildo y su obispo). A veces, esta clase de suscripciones ofrece más detalles acerca del proceso incorporando acciones que, aunque no se

81 Esta práctica se ha identificado en otras sedes como la compostelana: Vázquez Bertomeu 1997: 510.

82 Los medio racioneros no eran partícipes de la elaboración de régimen normativo, pero tenían derecho a mostrar su oposición. ACS, Registro de acuerdos capitulares C3, fo. 139v (1476, octubre, 15). citen textualmente, se presuponen de todo acto escriturado, como la revisión y cotejo del texto conocido como recognitio. ${ }^{83}$ La conservación de una de minuta sin validar de unas ordenanzas redactadas en julio de 1500 permite un reconocimiento visual de lo que estas actividades de composición y corrección podrían suponer. ${ }^{84}$ En el ejemplar se asienta la reunión capitular celebrada el 15 de julio de 1500 en la que se comisiona a dos canónigos para que entiendan las cuestiones matrices del estatuto y son diputados para que pidan a Diego de Castro, uno de los notarios del cabildo, que ponga por escrito lo que le indiquen y lo asiente en el denominado Libro de las Costumbres. ${ }^{85}$ Más adelante, figura en la minuta otro acto del 16 de julio en el que el notario asume el trabajo pertinente y relata en primera persona cómo fue llamado por los diputados para compendiar al menos una veintena de ordenanzas que aparecen a lo largo del texto; estas indicaciones son, en definitiva, muestras de la iussio-rogatio. ${ }^{86}$ Además, la minuta ofrece una serie de pistas que esclarecen el procedimiento de composición del documento final. El marcado estilo objetivo utilizado por el notario denuncia que la iniciativa era llevada a cabo por los canónigos comisionados, utilizando frases como dixeron que la costumbre muy antigua desta yglesia es... o los señores deán e cabildo e los señores deputados ordenaron que los testamentarios... ${ }^{87}$ Antes de escriturar el mundum (documento definitivo listo para validar) con base en la minuta, debió de producirse su revisión o recognitio. Esta se identifica por la disposición de anotaciones en los márgenes de algunos de sus folios, manuscritas por el propio notario según las indicaciones de los capitulares. La mayoría de estas notas completa y aclara los contenidos escriturados en el espacio central, subsanando posibles errores o ambigüedades en su comprensión, amén de completar olvidos de contenido plasmados en la primera composición. Por ejemplo, la ordenanza que regula la actividad del campanero al fallecer un capitular se completa con la nota marginal: y que cada clamor sea tan largo como un sexto de hora..$^{88}$

Con todo ello, se piensa que previamente pudo existir una fase de imbreviato o borrador, donde se fijaría un apunte o nota previa de mano del notario. La manifestación escrita que puede encajar con este procedimiento es el

83 Valga como ejemplo: (...) este público instrumento de estatuto e ordenança fis escribir e lo corregí e conçerté. ACS, Colección Diplomática, 15-14.

84 ACS, D-1073-1088, no 10.

85 (...) Asy mismo la orden que se ha de tener en el desyr de las missas que cada señor e benefiçiado es obligado de desyr para el señor e benefiçiado que fallesçiere (...) los dichos señores deán e cabildo cometieron las presentes cosas a los señores el liçençiado Rodrigo de León e Juan Muños, canónigos en la dicha iglesia e los deputaron para ello e que tomen consigo a Diego de Castro, benefiçiado en la dicha iglesia para que escriva lo que ellos ordenaren e lo ponga e asiente en el libro de las costumbres para que allí esté e finque en perpetua memoria. Ibídem., fo. 1r. Este caso no es el único ejemplo de comisión a canónigos para diseñar un estatuto, vid. nota 42.

${ }^{86}$ E después desto, en 16 días del dicho mes de julio, los dichos señores benefiçiados Rodrigo de León e Juan Muños, canónigos, con otros señores e canónigos que para ello llamaren, mandaron a mi, el dicho Diego de Castro, que escribiese e asentase las ordenaças siguientes con protestación que fisieron que non salirían de las costumbres antiguas... Ibídem., fo. $1 \mathrm{r}$

87 Ibídem., fols. $1 \mathrm{v}$ y $2 \mathrm{v}$.

88 Ibídem., fo. 2 r. 
asiento del acto en los libros de acuerdos o actas capitulares, o los registros personales del notario, de los cuales existen escasas noticias. En estos formatos, se estilaría la nota o apunte tomada en la reunión capitular, probablemente en libros manuales de tamaño cuarta (a modo de borrador) y después en libros mayores (en limpio). ${ }^{89}$ Un caso que puede servir como ejemplo es el estatuto de 1443, del cual se ha conservado el acta de la reunión capitular en la que se gestó. En ella, el secretario dejó constancia del otorgamiento del estatuto, describiendo someramente su materia y la presencia de testigos. ${ }^{90}$ Así, el contenido textual no se desarrollará en extenso como en el documento original conservado que, sin duda, fue compuesto a partir de otra redacción más completa. ${ }^{91}$ Corrobora esta aseveración la disposición del acta levantada por el secretario al citar que ordenaron un estatuto en que largamente se contiene todo. Así, los libros de acuerdos del cabildo segoviano recogen fundamentalmente breves apuntes de la otorgación de preceptos normativos, en los que se menciona la fecha, los presentes, un resumen del contenido y la relación de los testigos. Pero también se han localizado escrituraciones más extensas en estos libros, cuyo nivel de detalle supera los elementos citados e incorpora un largo recorrido textual que constituiría la exposición y la disposición del documento definitivo. Es el caso de un estatuto acordado en 1475 a la sazón de un pleito, del cual bien pudo sacarse instrumento público aunque no se tiene constancia de ello. ${ }^{92}$

No se conocen hasta la fecha prácticas de registro de esta clase de documentos. La única referencia es el códice manuscrito a comienzos del siglo XVI en el que se copiaron un conjunto de documentos institucionales del cabildo (actas conciliares, compromisos, bulas, sentencias, etc.), entre los que se encuentran la mayoría de estatutos medievales. Tampoco se han hallado noticias acerca de la tasación de los mismos, aunque se estima que el salario del secretario incluía la escrituración de todos los documentos emitidos en el seno capitular. Sobre la validación, se remite al epígrafe de este trabajo dedicado exclusivamente a sus elementos. Con toda probabilidad, su ejecución tenía lugar una vez configurado, escriturado y revisado el documento, materializando así su autentificación.

89 Este sistema parece ser el utilizado por los notarios y secretarios del cabildo segoviano, pero aun constituye una cuestión pendiente de estudiar a fondo, que se espera abordar en futuros trabajos. A priori, encuentra cierto parecido con el caso compostelano: Vázquez Bertomeu 1997: 521 y ss.

90 Este dicho día, estando el sennor cardenal en su cabildo capitularmente con el deán e cabildo de la dicha su iglesia, llamados por su canpana tannida segund ge lo han de uso e de costunbre de se ayuntar entre otros tractamientos que ende ovieron ordearon un estatuto sobre rrasón de los rrepartos de los bienes e heredades de la dicha iglesia en que enda disen dos prebendas para las visitar en cada uno e para los apear, una con el común e otra en las pitanças, que se contase en cada una tanto en como ganase un canónigo, e demas ge los benefiçiados que son absentes que paguen eso mismo los que non son benefiçiados e tienen prestamos asi de provisión de non e en qual manera devían contribuir a ello. ACS, Registro de Acuerdos Capitulares C-181(01), fo. 6v, (1443, octubre, 10).

91 ACS, Caja L-103.

92 ACS, Registro de Acuerdos Capitulares C4, fols. 112v-113v (1475, octubre, 24). Al final del asiento el secretario capitular hizo constar: otorgaron, iuraron inistrumentos con qualesquier claúsulas aunque sean de sustançia acostunbradas e non acostunbradas, e tal qual yo le signare.

\subsection{La forma de los documentos}

\subsubsection{Caracteres internos}

\section{Lenguas y estilo discursivo}

En lo que respecta a la lengua utilizada para su composición se ha observado una recurrencia al latín, especialmente en los ejemplares de los siglos XIII y XIV, y al castellano, para los documentos más modernos. Hecha esta apreciación, hay que señalar que los primeros estatutos redactados en castellano corresponden con los años 1311 y 1339. Posteriormente se volvió a recurrir a la lengua latina para componer los que se publicaron en 1350 y 1384, mientras que los documentos del siglo XV están en castellano en su totalidad. Además, hay que indicar la presencia de ambas lenguas en algunos de los documentos. Es el caso, precisamente, del recientemente citado estatuto de Pedro de Cuéllar de 1339, pues, a pesar de haberse utilizado el castellano, contiene unas cláusulas dispositivas en latín correspondientes a una inserción. El mismo fenómeno se halla en el estatuto de 1311, que extiende su data en latín. Asimismo, el estatuto de 1350, publicado por el mismo obispo, presenta la realidad inversa al disponer el latín de un modo predominante en su composición, pero incluye la data y la relación de testigos en castellano.

En lo que respecta al estilo de redacción utilizado para componer los documentos consta, tanto el subjetivo como el objetivo. Se sabe que esta distinción estilística corresponde con los modelos formularios carta y acta, respectivamente. La indistinta utilización de un modelo y otro para componer estos documentos es evidente. Si bien es cierto que el estilo subjetivo es propio de los documentos más tempranos, hay que decir que también está presente en fechas posteriores. Esto viene a corroborar que el contenido material de los documentos no está relacionado directamente con su modelo formal de redacción, tal y como se ha indicado en otros ámbitos..$^{93}$ La alternancia de ambos estilos tendrá su consecuencia en la redacción de los documentos, pues conlleva la variación de algunos aspectos del formulario textual, tal y como se verá a continuación.

\section{La estructura documental y sus fórmulas}

Por lo general, el protocolo de estos documentos, es decir, la primera parte de los mismos, posee tres elementos: invocación, notificación e intitulación. Quizá el elemento que ofrece menor variedad es la, no siempre presente, invocación verbal, que se expresa con la expresión in Dei nomine amen, junto a una sencilla cruz latina, ubicada en el centro superior de los ejemplares más modernos. Por el contrario, la notificación es una de las partes más diversas y se halla en todos los documentos analizados. Puede corresponder con fórmulas sencillas como noscant tam presentes quam futuris, ${ }^{94}$ pero en la inmensa mayoría de los casos la notificación especifica el tipo documental, sepan quantos este estatuto e ordenamiento vieren, ${ }^{95}$ manifiesto

93 La misma observación hizo la profesora Pilar Ostos sobre el conjunto documental de la catedral de Burgos. Ostos Salcedo 1994: 175.

94 ACS, Colección Diplomática, 6-1.

95 ACS, Colección Diplomática, 15-2. 
sea a los que el presente quaderno de estatutos vieren, ${ }^{96} \mathrm{y}$, a veces, hace alusión a su carácter público: sepan quantos este público instrumento de estatuto e hordenança vieren. ${ }^{97}$ Los documentos que se inician con la fórmula notificativa suelen estar redactados en estilo objetivo, aunque también pueden abrirse con la data. La intitulación y su tenor difiere, nuevamente, en función del estilo de redacción. También depende de los títulos asociados a la personalidad institucional del autor, o la inserción de la fórmula de reunión y lista de concurrentes. De este modo, es posible encontrar intitulaciones individuales en las que el obispo, en tanto autor moral, asume la acción jurídica y se presenta en solitario. En este caso, la intitulación es más o menos extensa en función de los cargos que sumara el prelado: Nos Fernandus, Dei gratia, episcopus segobiensis ${ }^{98}$; Nos, don lohan de Cervantes, por la miseraçión divinal, Cardenal de Sant Pedro ab vincula, administrador perpetuo de la eglesia e obispado de Segovia ${ }^{99}$; Don Juan de Medina, por la gracia de Dios e de la Santa Iglesia de Roma, obispo de Segovia, presidente de la Corte e Chancillería de Valladolid, por el rrey e rreyna, nuestros señores, e del su conseio. ${ }^{100}$ Por su parte, la intitulación colectiva suele estar relacionada con la composición del documento en estilo objetivo, pero no siempre: Nos Ferandus, Dei gratia, segobiensis episcopus voluntes put humana fragilitas sustinet impius opilas exemplar imitari, de voluntate consensii et consilio venerabilium dopni Garsie Sancti, decani et capituli segobiensis ecclesie. ${ }^{101}$ En lo que atañe a la dirección, en buena parte de las ocasiones se halla subsumida en la disposición, donde se estipula los destinatarios de la acción del documento. Pero a veces se incorpora seguida a la notificación, con un carácter más bien genérico: a todas las personas presentes e futuras, así eclesiásticas como seglares de cualquier estado o condición; ${ }^{102}$ a todos los fieles en leshu Christo. En este último ejemplar, de 1331 , se halla el único caso de saludo como fórmula de cortesía hacia los receptores del documento. Se expresa únicamente con la palabra salud. ${ }^{103}$

El carácter expositivo de la redacción indirecta se manifiesta al relacionar los presentes en la reunión capitular a modo de intitulación. Esta fórmula incorpora una lista de nombres a renglón tendido, intercalando ocasionalmente con la data y a veces recogiendo la presencia de notario y testigos. Para articular todos estos datos se usan encabezados del tipo: estando allí o estando presentes. El acomodo de los intervinientes se plasma según riguroso orden jerárquico, a saber, obispo, dignidades, canónigos, racioneros y medio racioneros, procurando una identificación manifiesta de cada uno de ellos.

El cuerpo textual es el núcleo de los documentos y contiene su esencia. Constituye un reflejo de los motivos que han llevado a la extensión del documento, representado por elementos como la exposición y, por supuesto, de la acción consecuente de los mismos, definida en la disposición y

\footnotetext{
96 ACS, D-1072, fo. 1v.

97 ACS, Caja H-88, fo. 1 r.

98 ACS, Colección Diplomática, 10-1.

99 ACS, Caja L-103.

100 ACS, D-1072, fo. 1v.

101 ACS, Colección Diplomática, 10-1.

102 ACS, Caja L-102, fo. 1r.

103 ACS, Colección Diplomática, 10-17.
}

amparada por el correspondiente aparato sancionador. Las exposiciones de los estatutos capitulares estudiados contienen las razones, causas o necesidades que fundamentan su otorgamiento y posterior escrituración, además de constatar algunas actuaciones acontecidas con anterioridad como debates, peticiones o acuerdos, muchos de ellos efectuados de manera colegiada. ${ }^{104}$ Aunque es cierto que algunos de los casos recogidos no presenta esta parte tan significativa, como ocurre con el estatuto sobre los pagos de luctuosa o reverende, existen otros en los que posee una gran extensión. Ocurre esto, por ejemplo, en el estatuto de Fernando Sarracín de 1311 en el que establece una serie de castigos a los que comentan delitos de injuria contra los clérigos, ${ }^{105}$ o con el de Juan de Cervantes de 1443, en el que se fijan unos pagos por parte de los prebendados de la catedral y su exposición explica que dicha carga se usará para sustentar la integridad de casas y molinos del cabildo. ${ }^{106}$ En otros estatutos la exposición advierte de la existencia de debates y contiendas sobre los asuntos que van a ser regulados por el documento. ${ }^{107}$ Del mismo modo, se hallan exposiciones breves como la del estatuto de Juan de Tordesillas de 1402, que justifica la fijación de un pago por la provisión de beneficios. ${ }^{108}$ En documentos redactados en estilo objetivo, cuya estructura documental se asemeja a la del acta notarial, la exposición comprende, además, la relación de presentes. Se ubican en este grupo, por ejemplo, el estatuto que otorgó el cabildo para tomar en arrendamiento varias de sus posesiones en $1383,{ }^{109}$ siendo el primer documento redactado en forma objetiva, o el que publicaron Juan Arias Dávila y el cabildo para regular el sistema de turnos en la provisión de vacantes. ${ }^{110}$

Llegado este punto, se entra de lleno en el terreno de la disposición. Se trata de un elemento que, dejando a un lado la reciente distinción entre documentos redactados en forma objetiva y subjetiva, siempre está presente en estos documentos normativos capitulares. Su composición y grado de desarrollo dependen de los contenidos ordenativos y del modo elegido por los autores para fijarlos. Tanto los verbos como las frases que inician el dispositivo son variados, desde la sencillez que ofrecen verbos de mandato como ordenamos, mandamos o estatuimos, hasta fórmulas algo más complejas y redundantes como ordenamos e establesçemos por la presente, ${ }^{111}$ pasando por otras que incluyen el reflejo del consenso, como previo acuerdo entre la autoridad episcopal y capitular: statuimus et ordinamus de consensus et beneplacito decani et capituli, ${ }^{112}$ o simplemente hordenamos con consentimiento. ${ }^{113} \mathrm{~A}$

104 Esta clase de elementos también se puede constatar en otros tipos documentales capitulares, como cartas de compromiso, sentencias, etc. Ostos Salcedo 1994: 179.

105 ACS, Colección Diplomática, 10-17.

106 ACS, Caja L-103.

107 ACS, H. 88, fo. 1r; ACS, D-1072, ff. 1v-2r.

108 ... considerando el provecho e validat de la dicha nuestra eglesia, por quanto ha en ella grand mengua de ornamentos e especialmente de capas e porque sea mejor servida la sobre dicha nuestra eglesia e las fiestas más honrradas por razón de las dichas capas. ACS, Colección Diplomática, 15-2.

109 ACS, Colección Diplomática, 13-19.

110 ACS, Caja H-88.

111 ACS, Colección Diplomática, 15-14.

112 ACS, Colección Diplomática, 10-1.

113 ACS, Caja L-102. 
continuación, se halla el conjunto de preceptos cuya extensión y forma de estructuración resulta variada. Mientras algunas cartas poseen una disposición concisa y escueta, otras se extienden largamente, para lo cual suelen recurrir a la división en apartados introducidos por la partícula latina item, o las castellanas otrosí, por quanto o porque. ${ }^{114}$

Sin duda, se puede decir que el preámbulo no es un elemento que posea excesivo protagonismo en los estatutos y ordenanzas bajomedievales del cabildo segoviense. Pero, como se ha reconocido en otros estudios, esta carencia no debe interpretarse como una reducción del rango de los documentos. ${ }^{115}$ Uno de los estatutos que posee preámbulo fue otorgado por el obispo Hugo de Lamanhania en $1384 .{ }^{116}$ Su contenido se basa en unos enunciados procedentes del Libro Sexto de las Decretales del papa Bonifacio VIII. ${ }^{117}$ Nótese la influencia del derecho canónico en el ámbito capitular a través de los textos de uno de los libros que pasó a formar parte del Corpus de Derecho Canónico cuando fue publicado en $1298 .{ }^{118}$

En cuanto al aparato sancionador y corroborativo, los textos analizados ofrecen variedad. Cierran el cuerpo documental cláusulas de tipo obligatorio y corroborativo, y en menor medida fórmulas preceptivas, prohibitivas y penales. Las cláusulas de tipo obligatorio suelen reflejar el juramento que los autores y receptores realizan sobre el cumplimiento de lo dispuesto: el qual dicho estatuto, nos el dicho obispo e los dichos deán e cabildo, juramos de lo guardar en forma devida. ${ }^{119}$ Como se ha visto anteriormente, el juramento constituye un importante acto por todo lo que supone la transmisión y el respeto de los preceptos legislativos con el paso del tiempo. Tanto es así que algunas cláusulas recuerdan esta esencia en su contenido obligando a cualquier miembro a que jure e sea tenido de jurar e de guardar este dicho nuestro estatuto e ordenança segund e como todos los otros estatutos e ordenanças desta dicha nuestra eglesia se suelen e acostumbrar jurar e guardar. ${ }^{120}$ Similares en tenor, existen casos de cláusulas preceptivas: mandamos guardar para siempre jamás. ${ }^{121}$ Por su parte, las cláusulas corroborativas garantizan la correcta hechura del documento, investido de todas las formalidades; en este sentido, su contenido refleja varias actuaciones como las suscripciones o la aposición del sello, tanto de forma individual como conjunta, así como la participación de un notario y testigos.

114 Esta forma de asentar la disposición, verbos incluidos, se encuentra en otras tipologías normativas como son las actas sinodales o conciliares.

115 Así lo indica la profesora Ostos Salcedo (1994: 176) sobre las constituciones y estatutos capitulares de la catedral de Burgos, carentes por lo general de este elemento.

116 ACS, Colección Diplomática, 14-7.

117 Liber Sextus Decretalium D. Bonifacii VIII, Títulus XI, capitulus II, ed. Roma, 1582, pp. 129 y 131 [en línea]. [Última consulta: 23 de noviembre de 2016], disponible en internet: https://books.google.es/ books? id=wY6E5JPDRWcC\&printsec=frontcover\&hl=es $\# v=$ onepage \&q $\& \mathrm{f}=\mathrm{false}$

118 El contenido del Liber Sextus Decretalium completa la labor desarrollada por Gregorio IX, compendiada en cinco libros, de lo cual toma la denominación de sexto. Su carácter es continuista y, a la vez, innovador al recoger y modelar preceptos del Digesto. Rodríguez Díez 2007: 330 .

119 ACS, Caja F-123, fo. 4r.

120 ACS, Caja L-103.

121 ACS, Colección Diplomática, 15-2.
Véase por ejemplo: El qual dicho estatuto e ordenança, firmado de nuestro nonbre e del dicho nuestro deán, (...) lo mandamos sellar de nuestros sellos, e por mayor firmeza rrogamos Andrés Ýnnigues en la dicha nuestra eglesia, notario público por la abtoridat apostólical, ante quien pasó este dicho estatuto e ordenança e todos los trabtados dél, que lo signase de su signo e a los presentes rrogamos que fuesen dello testigos. ${ }^{122}$ También se extienden otras cláusulas como las de tipo prohibitivo, aunque están menos representadas: e de non vernir contra ello nin contra cosa alguna dello, ${ }^{123}$ o no veniendo contra la sustançia del, ${ }^{124}$ así como otras de tipo penal: a qualquier o aquellos que lo fisieren ayudaran o consedieren o favor dieren o defendieren por ese mismo fecho, sea excomulgado. ${ }^{125}$

El escatocolo, parte final de los documentos, suele portar la data y la validación, ambas en sus múltiples modalidades. Ya se ha comentado que la expresión de la fecha a veces se halla en el comienzo de los documentos, bien de manera independiente siguiendo a la notificación o intitulación, bien intercalada con esta última, expuesta a renglón tendido. Pero también es frecuente encontrarla en el escatocolo, y de no ser así, a veces se estila en esta sección una fórmula en la que se recuerda la hechura del documento en un momento y lugar: que fue fecho e otorgado este dicho estatuto e (...) segund dicho es día, mes e año susodichos. ${ }^{126}$ La data puede expresarse de forma sencilla, es decir, mediante las partículas actum, datum, fecho o dado, dejando constancia de los datos topográficos y cronológicos. Para estos predominan la indicación del día y mes, usando la calendación romana en los ejemplares más tempranos, así como el año según la fórmula del año Domini, generalmente: Datum et actum Segobie, undecima die mensis maii, anno anatis Domini millesimo trecentesimo octuagesimo quatro. ${ }^{127}$ En dos de los instrumentos figura la data según el sistema de la era hispánica; uno combinado con el estilo actual ${ }^{128}$ y otro en solitario que, curiosamente está fechado el mismo año en que el rey Juan I de Castilla estableció la datación oficial mediante el sistema del año del nacimiento de Cristo, $1383 .{ }^{129}$ Otras, sin embargo, son más extensas, mencionado además el tenor documental y la reunión donde se trató o publicó el estatuto: en la dicha çibdat de Segovia dentro en el cabildo, que es en el palaçio del rrefitor de la dicha iglesia, martes diez y seys días... ${ }^{130}$ Incluso, pueden especificar alguna circunstancia extraordinaria, como la alteración del lugar acostumbrado de reunión: fecho e otorgado e hordenado en la eglesia perrochial de Sant Andrés, por la ocupación de la eglesia cathedral, donde de presente nos ayuntamos a los devinales ofiçios, veynte e nueve días... ${ }^{131}$

\footnotetext{
122 ACS, Colección Diplomática, 15-14.

123 ACS, Caja H-88, fo. 2r.

124 ACS, Colección Diplomática, 13-19.

125 ACS, Colección Diplomática, 10-17.

126 ACS, Colección Diplomática, 15-14.

127 ACS, Colección Diplomática, 14-7.

128 ACS, Colección Diplomática, 12-15.

129 ACS, Colección Diplomática, 13-19. Así lo señala acertadamente D. Hilario Sanz (1988: 86). En la plica de este ejemplar se escribió posteriormente la fecha según el sistema moderno.

130 ACS, Caja L-103.

131 ACS, Caja F-123, fo. 4v.
} 
Por último, se encuentra la validación. Al constituir un elemento de primer orden en el análisis diplomático, los elementos validativos y de autenticación se han recogido aparte. En este caso, simplemente se hará constar su localización al final de los documentos y su variada esencia. Aparecen elementos validativos de todos los partícipes del acto: los otorgantes (rúbricas, firmas autógrafas, sellos), los testigos (constatación textual) y el rogatario, la mayor parte de veces notario de la iglesia de Segovia o del cabildo catedral, público, apostólico, o ambas (refrendo y signo personal).

\subsubsection{Los caracteres externos}

\section{Materiales escriptorios}

El pergamino y el papel constituyen los materiales escriptorios sustentantes utilizados para escriturar los estatutos y ordenanzas capitulares, si bien con cierto predominio del primero sobre el segundo. La totalidad de los que datan de los siglos XIII y XIV, así como varios ejemplares del $\mathrm{XV}$ y de principios del XVI se conformaron en pergamino. Su formato, calidad y conservación son aspectos que se muestran variados. Independientemente de la orientación de la escritura, el tamaño y formato se ven afectados por la extensión, adaptándose a la disposición y a los elementos del texto. En cuanto a la calidad, predomina un rango intermedio, definido por su color tostado claro y un grosor moderado, aunque bien es cierto que algunos son de mayor categoría, probablemente obtenidos de animales más jóvenes. ${ }^{132}$ En general, su estado de conservación es bueno, aunque los hay que han sufrido cortes y desarreglos irregulares, o presentan humedades y arrugas que impiden la lectura de parte de su contenido. El papel se usó para escriturar algunos de los documentos originales del siglo XV, amén de las numerosas copias que se han conservado (coetáneas y posteriores). Su formato suele ser el pliego, pero también se manejó el modelo de cuarta. El material utilizado es de buena calidad, no habiendo sufrido excesivos desperfectos más allá de algunos cortes y rotos por dobleces y manejos posteriores. A pesar de ello, todo parece indicar que el cabildo tuvo predilección por el pergamino a la hora de poner por escrito sus ordenanzas, teniendo en cuenta la mayor resistencia y solemnidad de este material con respecto al papel.

Además de estos dos elementos, no hay que olvidar que algunos textos fueron escritos en otro tipo de soportes. Es el caso de las tablas de madera ubicadas en distintos lugares y espacios de la catedral, de las cuales existen algunas menciones expresas como la de la ordenanza de los capellanes hecha en 1420 y publicada de nuevo por Juan Arias Dávila, en su etapa como deán (ca. 1460). Este hecho fue reconocido por el escribano que compendió los estatutos en el códice manuscrito a comienzos del siglo $\mathrm{XVI}$, justificando con esta alusión que no copiase la ordenanza en el libro. ${ }^{133}$ Con toda probabilidad, y teniendo en cuenta prácticas como las lecturas periódicas ya mencionadas, el uso de esta clase

132 En este sentido, destaca el pergamino utilizado para confeccionar los estatutos de 1440 y de 1466.

133 Esta ordenança se fizo por el rreverendo señor don Juan Arias, deán, obispo que es agora de Segovia, la qual está escripta en una tabla e por eso no la escreví aquí. ACS, D-1072, fo. 38v. de soportes respondía a otro mecanismo publicitario que favorecía el conocimiento de lo reglamentado y en cierto modo su cumplimiento. ${ }^{134}$

\section{Tipos de escritura}

Nutrir este estudio de documentos que datan de un marco temporal tan amplio, explica el multigrafismo presente en los mismos. Dado el contexto geográfico e histórico cultural de las cartas, dominan los tipos góticos documentales castellanos en sus distintas modalidades. ${ }^{135}$ En este sentido, hay que hablar de buenos ejemplares de escritura minúscula diplomática y de privilegios, que abundan en las cartas de finales del siglo XIII y principios del XIV, así como en algunos del XV (Fig. 1). ${ }^{136}$ Estos tipos portan un cierto grado de cursividad a lo largo de los siglos XIV y XV, ${ }^{137}$ y algunos de ellos corresponden al tipo albalaes (Fig. 2). ${ }^{138}$ En general, estas letras presentan un módulo mediano y se disponen con elegancia guardando generosos espacios, tanto entre palabras como entre renglones. También, son frecuentes modelos más cursivos, pues están presentes la escritura precortesana ${ }^{139}$ y la cortesana, esta última solo para facturar documentos más humildes en papel. ${ }^{140}$ Acompañando a estas categorías, se observa un gusto por escriturar con modelos góticos que se acercan al ámbito librario, sobre todo, en algunos documentos del siglo $\mathrm{XV}^{141}$ Estos tipos son especialmente recurrentes en iniciales, palabras de comienzo de texto o destacadas del formulario, pero también se extienden en documentos íntegros donde se impregnan de un cierto ductus cursivo. De este modo, la presencia de caracteres librarios y cursivos en esta tipología documental se explica por la interrelación entre la escritura típica de los libros y la de los documentos, reconocida en el contexto cultural bajomedieval hispano. ${ }^{142}$ A pesar del juego existente en el uso del latín y del castellano, especialmente en los documentos de la decimocuarta centuria, no se han detectado casos de multigrafismo asociado al uso de distintas lenguas, fenómeno definido como «bilingüismo-bigrafísmo». ${ }^{143}$ Por el contrario, sí es habitual encontrar multigrafismo en diferentes partes de un mismo documento. Así, se combinan estilos librarios en invocaciones o notificaciones o palabras destacadas del cuerpo, con góticos documentales cursivos para el resto del texto o presentes en la suscripción notarial. ${ }^{144}$

134 Se desconoce el aspecto externo de estas tablas, pero un ejemplar del siglo XVIII que decora actualmente la sala de consulta del archivo, precisamente sobre el método de observancia de los capellanes, puede representar una idea más o menos fidedigna de estos objetos.

135 Para concretar los tipos gráficos, de nuevo, se siguen las pautas recogidas en Marín Martínez 1991.

136 ACS, Colección Diplomática, 6-1; 8-15; 10-2; Caja L-102 (Víd. Fig. 1).

137 ACS, Colección Diplomática, 10-1; 10-2bis; 12-8; 12-15.

138 ACS, Colección Diplomática, 10-17 (Víd. Fig. 2).

139 ACS, Colección Diplomática, 14-7; 15-2, 15-13; 15-14.

140 ACS, Caja F-123; Caja H-88.

141 ACS, D-1072.

142 Premisa declarada y abordada por la profesora Camino Martínez (1985: 387), quien reconoce la necesidad de revisar la distinción entre góticas librarias y cursivas al constatarse la presencia de las primeras en el ámbito de las segundas.

143 Camino Martínez 1999.

144 Un buen ejemplo de este último fenómeno es el cuaderno de estatutos de 1504, escriturado íntegramente con una gótica libraria elegante que contrasta con la cortesana del refrendo notarial. ACS, D-1072. 
FIGURA 1

Estatuto de Fray Lope Barrientos y el cabildo catedralicio, 1440

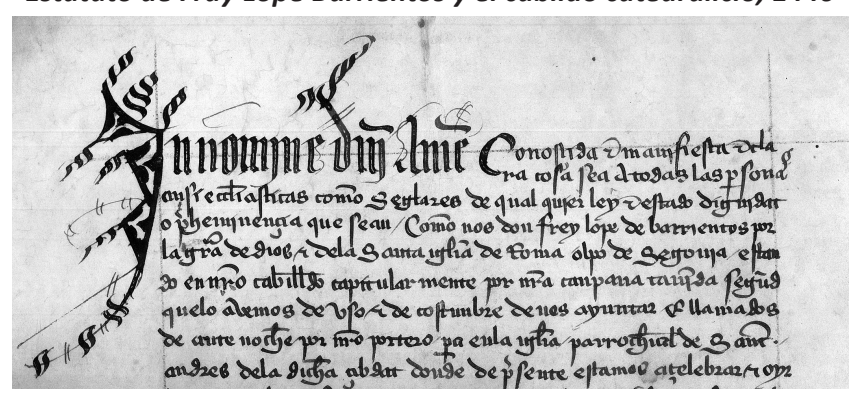

Fuente: ACS, Caja L.102.

FIGURA 2

Estatuto de Fernando Sarracín, 1311

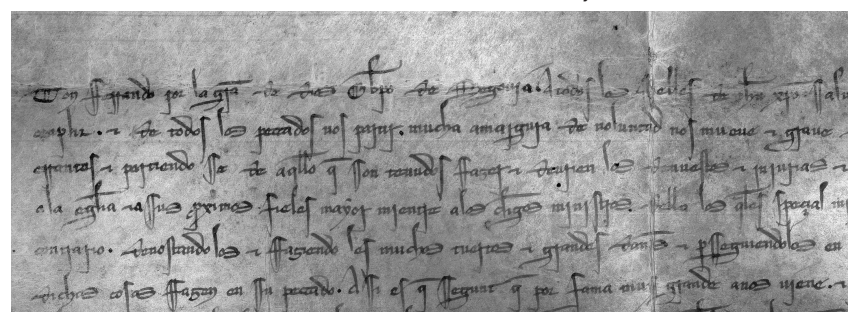

Fuente: ACS, Colección Diplomática, 10-17.

\section{Signos de validación y autenticación}

Para asegurar su vigor dispositivo y fuerza institucional, los estatutos medievales del cabildo catedralicio de Segovia, al igual que otros muchos de sus documentos, debieron ser debidamente validados y autenticados. De este modo se utilizó una serie de elementos que se suceden y alternan en los distintos momentos del período estudiado, respondiendo en líneas generales a los métodos y sistemas de validación del contexto histórico-documental.

La presencia de sello colgante de cera es casi constante en todos los ejemplares, siendo esta tipología documental una de las pocas que portó este elemento de autenticación. Concretamente, los estatutos ubicados cronológicamente entre 1258 y 1443 fueron validados con sellos episcopales y capitulares. En la segunda mitad del siglo XV el sello fue eliminado de la praxis autenticativa y la validación recayó en la fe notarial, materializada con signo y suscripción de un notario público episcopal o apostólico.

El aspecto general de los sellos se asemeja a los modelos eclesiásticos ampliamente extendidos en la institución. ${ }^{145}$ Esto es, compuestos de cera (roja, ocre o marrón), de formato ovalado o circular, y pendientes de cintas de cuerda o seda, roja y verde principalmente. Muchos se conservan fragmentados y mutilados, y otros se han perdido. Los sellos episcopales suelen traer un campo con tipos personales e identificativos, dominando la figura del prelado de pie o sentado, con elementos distintivos como el báculo y la mitra, además de los hábitos canónicos. El campo está rodeado por distintas leyendas escritas en caracteres góticos capitales en las que se incluye el nombre y la titulatura

145 Riesco Terrero 1983; Pueyo Colomina 2014: 152-158; Lera Maíllo 2014.
(FERNANDUS, EPISCOPUS SEGOBIENSIS), ${ }^{146}$ acompañada en ocasiones por la advocación religiosa DEI GRATIA o la palabra SIGILUM. Por su parte, el campo del sello capitular suele traer motivos hagiográficos, predominando la figura de la Virgen en majestad y bendiciendo a otra imagen, probablemente el deán, ambas cobijadas bajo una estructura de ventanales de estilo gótico; rodeando la leyenda: CAPITULI SEGOBIENSIS ECCLESIE. ${ }^{147}$

Otro elemento validativo lo constituyen las suscripciones de los otorgantes de la norma. En primer lugar, habría que hablar de la suscripción episcopal y, en segundo, la de los clérigos capitulares. La firma autógrafa del obispo se suele ubicar en primer lugar debajo del cuerpo documental y ocupa una posición central. De las suscripciones de los capitulares suele destacar la del deán, incorporada y dispuesta cerca de la del obispo, mientras que las restantes, principalmente pertenecientes a dignidades y canónigos, se acomodan debajo, generalmente en dos columnas. Las suscripciones están formadas por el nombre personal y el rango beneficial capitular (arcedianus, canonicus, socius, etc.). Ocasionalmente se completan con frases del tipo propia manu scripsi o hiis interfui et subscripsi, propias de ejemplares de los siglos XIII y XIV. ${ }^{148}$ Formalmente, este elemento se asemeja a las columnas de confirmantes típicas de documentos reales solemnes, como los privilegios. Una observación paleográfica aventura a corroborar que se trata de suscripciones autógrafas, constatando el ejercicio personal de la suscripción en lugar de la intervención del amanuense que escrituró el documento. ${ }^{149}$ Las suscripciones se hallan en ejemplares de la decimotercera centuria y comienzos de la decimocuarta, aunque también están presentes en el estatuto de 1402 y en el de 1436. Es posible que en algunos documentos no se llegasen a escriturar en su totalidad. Ocurre esto en dos de los tres originales múltiples del estatuto sobre los derechos de luctuosa o reverende de 1303, que solo presentan un escaso número de suscripciones, lo que puede asociar un carácter secundario a las mismas. ${ }^{150}$

Por último, como ya se ha venido anunciando, la participación de la institución notarial en el proceso de validación de documentos estatutarios capitulares constituye un factor muy importante. Su presencia tiende a ser cada vez mayor según avanza en el periodo estudiado. De esta manera, el primer documento que contiene la signatura notarial es el estatuto de 1303. El signo de Pedro López, notario público y jurado, está presente en los tres originales múltiples que se confeccionaron. ${ }^{151}$ Un notario no volverá a tomar parte de la validación hasta los estatutos de 1383 y 1384, siendo constante a partir de entonces. El modo de autenticar el documento consiste en la extensión de su suscripción más o menos desarrollada, siempre localizada al final del instrumento y acompañada del

\footnotetext{
146 ACS, Colección Diplomática, 10-2bis.

147 Ídem.

148 Ídem.

149 Riesco Terrero 1983: 449.

150 ACS, Colección Diplomática, 8-15, 10-1, 10-2bis.

151 Ego uero Petrus Lupi, notarius antedictus ad requisitonem et instancia rreverendi patris domini domni Ferdinandi episcupi memorati et venerabilium uirorum domnorum dompi Garsie Sancii, decani et capituli eiusdem his omnibus inter fuit et manu propia conscripsi et in forma publicam redegi et in testimonium omnium premisorimus et quodlibet eorundem meum signum aposui fuerum. ACS, Colección Diplomática,
} 10-1, 10-2, 10-2bis 
signun tabellionis o signo notarial propio, cuyo diseño varía en función del tipo de notario (público, apostólico, etc.). Por su nivel ornamental y estilístico destaca el signo del notario apostólico Andrés Íñiguez, ubicado en los estatutos de 1436, 1440 y $1443 .{ }^{152}$ Véase a continuación, junto a otros elementos validativos comentados.

\section{FIGURA 3}

Estatuto de Juan Vázquez de Cedepa y el cabildo catedralicio, 1436

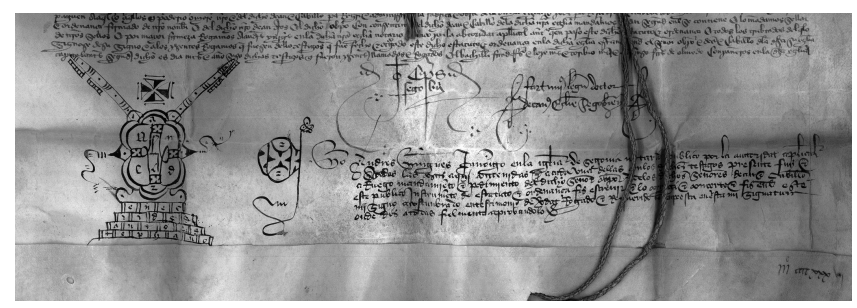

Fuente: ACS, Colección Diplomática 15-14.

\subsection{Tradición documental}

La tradición, es decir, el modo de transmisión del documento, es uno de los aspectos más importantes de la Diplomática. El análisis de los caracteres extrínsecos e intrínsecos esclarece la condición de original o copia de los documentos, y tras los análisis realizados sobre los ejemplares segovienses, se ha identificado varias de estas categorías.

\section{Originales y originales múltiples.}

La mayoría de los documentos que han constituido la base de este trabajo son originales, es decir, que han llegado a la actualidad tal y como fueron emitidos. La autoría compartida y el alcance institucional de los estatutos, así como su habitual consulta, manejo o lectura en diferentes contextos, pudieron ser los motivos de la extensión de algunos originales múltiples. El caso más temprano identificado corresponde con el estatuto recientemente citado de 1303, a través del cual el obispo concedió una rebaja en la percepción de los derechos de luctuosa. ${ }^{153}$ Se conservan tres instrumentos originales escritos sobre pergamino, dos de los cuales parecen haber sido compuestos en algún momento posterior. Aunque estos ofrecen una imagen más cuidada, carecen de ciertos elementos formales. ${ }^{154} \mathrm{El}$ que podría considerarse como primer original consta de todos los elementos validativos que normalmente se hallan en este tipo de cartas: suscripción autógrafa episcopal, suscripciones de una veintena de miembros del cabildo (principalmente dignidades y canónigos), suscripción y signo del notario y, por último, la aposición de los sellos pendientes del obispo y cabildo. Por su parte, los otros dos documentos presentan un acabado más cuidado, por ejemplo, en cuanto a ejecución de escritura se refiere. Su validación se efectúa mediante el signo notarial y de los dos sellos eclesiásticos, pero carecen, sin embargo, de las suscripciones capitulares, habiendo espacio más que suficiente para ellas, lo que lleva a pensar que fueron confeccionados posteriormente.

\footnotetext{
152 ACS, Colección Diplomática, 15-13; 15-14, Cajas L-102 y F-132.

153 ACS, Colección Diplomática, 10-2.

154 ACS, Colección Diplomática, 10-1 y 10-2bis.
}

El otro caso de original múltiple se identifica en el estatuto de 1440, promulgado conjuntamente por el obispo fray Lope de Barrientos y el cabildo. Existen dos ejemplares de formato similar (cuaderno de cuarto de folio) pero con una diferencia material manifiesta: uno de ellos está escriturado sobre papel, ${ }^{155}$ siendo el primer documento normativo sobre esta materia escriptoria, y otro en pergamino. ${ }^{156}$ Se trata de un aspecto importante, puesto que condiciona varios caracteres externos del documento, como la escritura o los elementos validativos, afectando a su imagen definitiva y a su solemnidad. La escritura gótica del ejemplar de pergamino se acerca a la documental de privilegios, aunque la invocación y las palabras del dispositivo se han revestido de estilo librario (Fig. 2). Por su parte, el documento en papel posee una escritura gótica cortesana, sin excesivos lujos decorativos, que corresponde con la del notario que suscribe, Andrés Íñiguez. Ambos pasaron ante él, pues estampa su signo en los dos originales, acompañado de una suscripción que presenta alguna variación de contenido y de orden de palabras. El ejemplar de pergamino conserva los dos lemniscos cosidos a modo de nervios librarios, mas los sellos se han perdido. El de papel no tiene restos de algún tipo de sellado y ello se explica porque el uso de sellos de cera pendientes no suele ir asociado a documentos escritos en papel. Así, llama la atención cómo, paradójicamente, el notario hizo constar en su suscripción la aposición del sello en este original de papel, no así en el de pergamino, que tendría mayor sentido. ${ }^{157}$ Aunque es cierto que la cláusula corroborativa que anuncia la aposición sigilar está presente en el tenor de ambos originales, la variación señalada sobre la suscripción notarial induce a pensar que el ejemplar de pergamino pudo ser el primer original, de mayor solemnidad y con la aposición de los sellos colgantes, y el documento en papel un segundo original múltiple escrito poco después.

\section{Las copias y sus tipologías}

Muchos documentos estatutarios han llegado a la actualidad en forma de copias. De nuevo, en este apartado se debe hablar de variedad ya que, según la cercanía con respecto a los documentos originales, se han localizado diferentes tipos. Existen numerosos ejemplos de copias simples, sin certificar, efectuadas a lo largo de la Edad Moderna. Pero también se han localizado copias autenticadas conformadas en el contexto bajomedieval, así como copias simples de otras auténticas. A continuación se tratan algunas de estas últimas con más detenimiento.

\section{- Copias certificadas:}

Dentro de este grupo, predominan los traslados notariales y judiciales. Los primeros pasaban únicamente ante notario; en los segundos era un juez quien interponía la

\section{ACS, Caja F-123.}

156 ACS, Caja L-102.

157 (...) a rruego e pedimiento e otorgamiento por los dichos sennores obispo, deán e cabildo, este estatuto escreví e fis en él este mi signo uno con los sellos de los dichos sennores obispo y deán e cabildo... ACS, Caja F-123. (...) a rruego e otorgamiento del dicho sennor obispo e de los dichos sennores deán e cabildo, este público instrumento de estatuto fis escrevir e fis en él este mi signo acostunbrado en testimonio de verdad... ACS, Caja L-102. 
autoridad y decreto para autorizarlo, aunque el notario también se hacía partícipe de esa autorización. ${ }^{158}$ Los traslados judiciales suelen ser ricos en información puesto que reflejan el proceso a través del cual eran autorizados. Para ilustrarlo, se tomará como ejemplo el traslado del estatuto de 1443 , sacado en $1453 .{ }^{159}$ La fórmula diplomática se identifica con el acta, (por lo cual este tipo de copias certificadas también recibe el nombre de traslado acta) y su estructura documental está organizada en una primera parte que alberga la data y a continuación un largo expositivo que contiene la fórmula de reunión de autoridades presentes y del notario, incorporando después el documento en forma extensa. Después, el expositivo recoge con claridad cómo se presentó el estatuto original y de qué modo fue identificado por la autoridad. Su reconocimiento se fundamenta en la observación de sus caracteres más destacados, como el contenido material, el soporte o los elementos validativos. ${ }^{160}$ Después de insertar el contenido íntegro, la exposición recoge los motivos por los que se ha de sacar el traslado y se hacen constar los efectos jurídicos, así como los actos simbólicos que rodean a este proceso. ${ }^{161}$ La copia se autoriza con la facultad del juez y finaliza con la suscripción y aposición del signo, en este caso, del escribano público.

Uno de los estatutos del que más se extendió copia certificada fue el que versa sobre el oficio de deán, dispuesto en 1339. Se conserva un traslado notarial, como prueba documental de un proceso judicial de 1480 entre el obispo y el deán al que se halla cosido. ${ }^{162}$ Otro ejemplar fue facturado en 1412 por Andrés González, notario de la iglesia de Segovia. De este último ha llegado a la actualidad una copia simple del siglo XVI. ${ }^{163}$ También, existe un traslado judicial

158 Ostos Salcedo 2005: 116-117.

159 ACS, Caja F-132.

160 paresçió y presente Diego Garçía de Oterdesillas, presbítero de la dicha iglesia en nombre e como procurador que es de los sennores deán e cabildo de la dicha iglesia, e presentó e leer fiso por mí, el dicho notario, un estatuto de la dicha iglesia escripto en pargamino, signado de notario público apostólico e sellado con dos sellos de çera pendientes en cuerdas de seda verdes e coloradas, su thenor del qual dicho estatuto de verbo ad verbum es este que se sigue. Ibídem., fo. 1r. La descripción encaja con el documento original conservado, ACS, Caja L-103. Esta forma de reconocer los documentos debía ser muy habitual por parte de los notarios y secretarios del cabildo, a juzgar por las numerosas menciones recogidas en las actas capitulares, de similar contenido.

161 (...) por quanto en el dicho nombre se tenía quel dicho estatuto se podía perder por fuego o por agua o por rrobo o por otro caso fortuyto de los que el derecho pone, de lo qual podría venir mucho daño e pérdida a los dichos sennores deán e cabildo, sus partes. Por ende ge le pedía e pidó que aprobase e conpliese a mí, el dicho notario, que sacase e fisiese sacar el dicho estatuto original un traslado, dos o más quantos menester oviese e los sygnase de mi signo en pública forma, al qual traslado o traslados asy sacados interpusiese a ellos e a cada uno dellos su abtoridad e decreto para que valiese e fisiese fe donde quier que parasçiese, bien como facía fe el dicho estatuto original. E luego, el dicho sennor vicario tomó en sus manos el dicho estatuto original e leyole e caçole e dixo ge lo fallava e falló non rroto nin tançilado nin en alguna parte sospechoso antes de todo (...) por ende, dixo que mandava e mandó a mí el dicho notario que sacase o fisiese sacar uno traslado, dos o más del dicho estatuto e los concertase con el fielmente e sygnase de mis syngo en pública forma, e asy fecho que interponía e interpuso su abtoridad e decreto aquel que en tal caso podía e de derecho debía para que valiese e fesiese fe cada uno de los dichos traslados asy en juysio como fuera del donde quier que paresçiese bien como facia fe. ACS, Caja L-103, fols. $6 \mathrm{r}$ y $6 \mathrm{v}$.

162 ACS, Caja H-50bis; Bartolomé Herrero 2003: 658.

163 ACS, Caja L-102. del estatuto de los turnos (1465) mandado sacar en 1469 por Juan Fernández Quijada, vicario episcopal en Turégano, villa de señorío episcopal, y validado por el escribano público de la misma, Juan Alfonso de Turégano. ${ }^{164} \mathrm{El}$ tenor expositivo es muy similar al traslado de 1453 , ya citado.

\section{- Copias simples, insertos y memoriales:}

Muchos de los estatutos capitulares del cabildo segoviense han llegado a la actualidad en forma de copias simples, sobre las que no recae ningún tipo de fe notarial y, por tanto, validez jurídico-diplomática. ${ }^{165}$ Aunque esta labor pudo comenzar más temprano, existiendo, por ejemplo alguna copia autógrafa del siglo $\mathrm{XV},{ }^{166}$ se reconoce una considerable proliferación de este tipo de copias a partir de la decimosexta centuria que continúa posteriormente. No es muy frecuente, pero se constatan ciertos insertos parciales en algunos diplomas normativos originales. Un claro ejemplo lo constituye el estatuto de 1339 , donde se acomoda de forma literal un fragmento normativo anterior, reconociéndose además la pesquisa previa que se hizo sobre el asunto y la asunción que se hizo de la misma como su fuente del derecho capitular. ${ }^{167}$ Otros casos documentados recogen un simple extracto o resumen de contenido, como por ejemplo en el estatuto de las misas de 1500 del cual ya se habló anteriormente. ${ }^{168}$

Para completar esta revisión, debe mencionarse que también existen escritos de relación como los inventarios o memoriales que datan de los siglos XVI y XVII. Se trata de documentos de tipo enumerativo, descriptivo o "de noticia», con un carácter meramente testimonial. ${ }^{169}$ Por lo general, son simples listados de los documentos medievales conservados por el cabildo, en los que constan los otorgantes, la materia y la fecha. Uno de los más tempranos data de principios del siglo XVI y corresponde con cinco folios de papel, escriturados por ambos lados. ${ }^{170}$ Con probabilidad, este tipo de material escrito existió mucho antes. Prueba de ello se encuentra en el libro compilatorio de estatutos en el que se recogen noticias simples de varios ordenamientos y estatutos de las primeras décadas del quinientos con una forma de asentarlos que difiere notablemente de la que predomina en el códice. ${ }^{171}$ Además, el encabezado que los introduce y

164 ACS, Caja F-145. Probablemente, Juan Arias Dávila precisó de una copia debidamente autorizada de este estatuto en un momento en que debía operar desde su refugio señorial, pues había sido expulsado de Segovia tras su reciente enemistad con el rey Enrique IV, señor de la ciudad.

165 Marín Martínez 1991, Tomo 2: 251.

166 La copia autógrafa es aquella «escrita por la misma mano que escribió el original». Ibídem: 251-252.

167 (...) y porque se falló por constituçión escripta y çierta qual es el offiçio (...) ponemos en esta carta, de consentimiento del deán y del cabildo, qual es el offiçio y poderío del deán, el qual offiçio y poderío non le tomamos de nuestro mas tomámosle de los libros y testimonio de las costumbres y de las ordenaciones que fallamos en la nuestra yglesia y lo que fallamos según dicho es esto que sigue. ACS, Colección Diplomática, 12-8.

168 En este caso se trataba de una concordia. Vid. nota 52.

169 Riesco Terrero 1995: 414.

170 ACS, Caja F-123. Memoria de los estatutos.

171 ACS, D-1072, fols. 37r-39v. Llama la atención que de estas ordenanzas y estatutos no ha quedado ningún documento (original o copia) ni se tiene noticia de ello hasta la fecha. Probablemente no se sacó escritura alguna. 
el estilo objetivo recurrente en todos los asientos de este conjunto hace pensar que el escribano del libro tuvo delante un memorial similar a los que aquí se han expuesto como típicos de los siglos posteriores. ${ }^{172} \mathrm{~A}$ ello habría que sumar el propio memorial utilizado para el juramento de estatutos, ya mencionado en otra parte de este trabajo.

Por último, se han localizado copias en formato libro o in libris conscriptae, ${ }^{173}$ que vienen a terminar de completar la gran variedad en lo que respecta a tradición documental. En primer lugar, el códice D-1072 compuesto en torno al año 1500 , mencionado ya en varias ocasiones. ${ }^{174}$ Corresponde este a un libro de noventa y cuatro folios manuscritos, en el que están copiados estatutos, ordenanzas capitulares y otros documentos tocantes al cabildo como actas de concilios provinciales, bulas papales o cartas reales. Tanto por su contenido como por su forma constituye un objeto de estudio muy interesante que se espera abordar en futuros trabajos. En segundo lugar, existen otros ejemplares más tempranos, escritos en algún momento de mediados del siglo XIII, cuyo contenido compila la labor legislativa del cardenal Gil de Torres junto a otros documentos tangenciales a su labor y publicados años después. ${ }^{175}$ Su razón de existencia, probablemente al igual que el D-1072, responde a una intención de salvaguardar la memoria y los derechos del cabildo, o a algún tipo de necesidad institucional de la época. ${ }^{176}$

\section{CONCLUSIONES}

Este trabajo ha pretendido ofrecer una amplia revisión sobre la normativa medieval de la catedral de Segovia y la producción escrita asociada a ella. Los estatutos capitulares destacan por ser las primeras definiciones de orden jurídico e institucional que van a configurar la jerarquía y funciones del cabildo. Los primeros pasos de articulación normativa se sucedieron a raíz de la separación de las mesas episcopal y capitular, momento a partir del cual comenzaron a sucederse las distintas ordenanzas, constituciones y estatutos. Como se ha visto, el proceso de composición no estaba exento de complicaciones, pues en origen su otorgamiento respondía a una competencia jurisdiccional repartida entre el cabildo y el cabildo catedral. La documentación desvela

172 Esta son las ordenanças que fizieron los señores deán e cabildo en la iglesia de Segovia ansy para en el coro como para en el cabildo e en la iglesia e fuera della. Primeramente, año de 1416. Este año fue ordenanda esta ordenaçión... ACS, D-1072, fo. 37r.

173 También identificados como «códices diplomáticos manuscritos de contenido jurídico-legal contendores de copias simples de estatutos» o «códices y manuscrito de contenido unitario o misceláneo». Ibidem., pág. 415.

174 ACS, D-1072.

175 ACS, B-291 y B-304; Villar García 1990: 216-240; Bartolomé Herrero 2003: 526 y 528. En su estudio monográfico sobre la diócesis de Segovia, Peter Linehan anexa un documento extra que no se encuentra en los citados códices, sino en un tercero custodiado actualmente en la Biblioteca Británica. Se trata de una carta declarativa del cabildo catedral de Segovia en la que pide al futuro obispo que modificase unos contenidos del conjunto ordenativo del cardenal. Fue publicada un día antes de ser elegido obispo Fernando Velázquez. Linehan 1981: 204.

176 La existencia de este tipo de libros se ha constatado en otros ámbitos como Santiago de Compostela, si bien guardando ciertas diferencias que afectan a su esencia, contenido y formalidad. Vázquez Bertomeu 1997: 519; Ramos Merino 2012: 255 (nota 1392); Belmonte Fernández 2014. con cierta claridad ese reparto con preponderancia del protagonismo episcopal, así como la relevancia de algunos momentos y actos a la hora de su diseño, como las reuniones del pleno capitular o la colaboración de canónigos y expertos, en derecho en tanto asesores para componer los textos. Al igual que otras sedes castellanas, la catedral de Segovia precisó de un amplio marco de actuación para ordenar y delimitar las funciones que le eran propias, donde tienen cabida cuestiones orgánico-funcionales, económicas, de culto, de comportamiento, etc. Además, se han identificado mecanismos de anclaje normativo que permitían conocer, hacer respetar y extender en el tiempo el corpus, como las lecturas periódicas o el juramento de provisión.

Pero todo lo indicado no sería posible sin los pertinentes recursos gráfico-documentales. A pesar de que la costumbre era una fuente de derecho importante en el período, la proliferación de la escritura y del derecho escrito, a la par de otros elementos histórico-culturales, hizo que los cabildos catedrales dispusieran por escrito algo tan fundamental como sus normas y reglamentos. Así, el cabildo catedral de Segovia, muchas veces con la iniciativa del obispo, ordenó la escrituración de una serie de documentos y otros materiales a través de los cuales fijó y publicitó su normativa. Los estatutos, ordenanzas, constituciones y algunas otras tipologías como las cartas de concordia son las principales denominaciones. Desde sus elementos internos, como la forma de composición, la lengua o la estructura diplomática, hasta los caracteres externos como los tipos de escritura o los elementos validativos, sin dejar de lado cuestiones relevantes de tradición documental, se advierte que esta tipología aglutina un amplio abanico de recursos escriturarios y documentales típicos de su contexto histórico y cultural. En lo que respecta a su génesis, se han planteado unas posibles vías de composición documental, esperando que puedan ser ampliadas y mejoradas al hilo de futuras investigaciones. Según las valoraciones propuestas, se estima que los instrumentos estatutarios eran ordenados por el obispo diocesano y el cuerpo clerical del cabildo, especialmente sus miembros destacados. En esta labor, tomó especial significado el personal escriturario de la catedral desde comienzos del siglo XIV y, paulatinamente, el colectivo notarial fue adquiriendo mayor implicación en su elaboración, tanto en lo que respecta a la composición, como a la validación de los documentos. Los rasgos formales de los documentos guardan ciertas similitudes con ejemplares de otras sedes como Burgos o Toledo, así como con otras tipologías cercanas, como las actas sinodales. Se ha observado una cierta evolución en todo el conjunto, especialmente en cuestiones gráficas, pero también en las relativas al formulario, estructura y procedimientos de validación. En lo que respecta a la tradición documental se han identificado casi todas las formas posibles: originales, originales múltiples, traslados notariales, libros de copias, copias simples, etc., cuya razón de ser estriba en necesidades como la preservación de los instrumentos y la defensa de su contenido. También, se ha constatado su carácter publicitario al documentarse la exposición en espacios catedralicios y lecturas públicas de forma periódica. En definitiva, un acercamiento nutrido que se espera poder completar con la visión que aporten futuras investigaciones sobre la documentación del cabildo segoviense. 


\section{FUENTES}

Archivo Catedralicio de Segovia. ACS:

Colección Diplomática, pergaminos: 6-1, 6-2, 8-15, 10-1, 10-2, 10-2bis, $10-17,11,6,12-8,12-15,13-19,14-7,15-2,16-8$ bis, $15-13$ y $15-14$.

Serie 'Actas Capitulares', volúmenes C-3, C-4 y C-5.

Cajas: F-29, F-123, F-132, F-145, H-50-bis, H-88, H-89, L-102, L-103, D-1072 y D-1073-1088.

Códices B-291 y B-304.

Archivo Diocesano de Segovia. ADS

Legajo 2058

Bartolomé Herrero, Bonifacio. 2003. "Catálogo de los documentos medievales relativos a los obispos de Segovia y a las instituciones eclesiásticas de la ciudad (1107-1398)». Anthologica annua 50: 417-797.

García y García, Antonio. 1993. Synodicon hispanum. Ávila y Segovia. Madrid: Biblioteca de Autores Cristianos.

Luis López, Carmelo. 2004a. Estatutos y ordenanzas de la iglesia catedral de Ávila (1250-1510). Ávila: Ediciones de la Obra Cultural de la Caja de Ahorros de Ávila.

Sanz Sanz, Hilario. 1988. Catálogo de la colección diplomática medieval (1115-1500) del Archivo Catedralicio de Segovia. Segovia: Caja de Ahorros y Monte de Piedad de Segovia.

Villar García, Luis Miguel. 1990. Documentación medieval de la catedral de Segovia (1115-1300). Salamanca: Ediciones Universidad de Salamanca y Ediciones Universidad de Deusto.

\section{BibLIOgRAFíA}

Bartolomé Herrero, Bonifacio. 1998. «El obispo Fernando Sarracín y el supuesto sínodo diocesano de Segovia de 1303». Anuario de Estudios Medievales 28: 679-694. https://doi.org/10.3989/ aem.1998.v28.i0.604

Belmonte Fernández, Diego. 2014. «Borradores, originales, copias y recopilaciones: los Libros de Estatutos del Cabildo catedralicio sevillano». Historia. Instituciones. Documentos 41: 45-74.

Camino Martínez, María del Carmen. 1985. «Escritura latina en la Plena y Baja Edad Media: la llamada "Gótica libraría" en España». Historia. Instituciones. Documentos 12: 377-410.

Camino Martínez, María del Carmen. 1999. "Bilingüismo-bigrafismo, un ejemplo sevillano del siglo XV». En Actas del // Congreso Hispánico de Latín Medieval (León, 11-14 de noviembre de 1997), coordinado por Maurilio Pérez González, Vol. 1, 385-392. León: Universidad.

Chacón Gómez-Monedero, Antonio. 1996. «Consideraciones codicológicas y paleográficas en torno a unos Estatutos capitulares conquenses del siglo XV». Ciudad de Dios: revista agustiniana 209, 3: 689-725.

Costa Belda, Enrique. 1978. "Las constituciones de Don Raimundo de Losaña para el cabildo de Sevilla (1261)». Historia. Instituciones. Documentos 5: 169- 233.

Cotano Olivera, Fátima. 2009. "Los estatutos capitulares de la iglesia de Coria (1586)». Cauriensia IV: 461-532.

Díaz Ibáñez, Jorge. 1998. La organización institucional de la Iglesia en la Edad Media. Madrid: Arco-Libros S. L.

Díaz Ibáñez, Jorge. 2003. Iglesia, Sociedad y Poder en Castilla. El obispado de Cuenca en la Edad Media (ss. XII-XV). Cuenca: Alfonsípolis.

Fliche, Agustín y Víctor Martín (dirs.). 1976. Historia de la Iglesia. Valencia: Edicep.

García Hernando, Julián. 1970. «Apuntes para la historia de la diócesis de Segovia». Estudios Segovianos 64: 119-145.

García Mota, Francisco. 1993. «El primer cabildo catedral de Málaga y el códice de sus estatutos aprobados en 15 de junio de 1492». Memoria ecclesiae IV: 241-247.

Granado Hijelmo, Ignacio. 2010. «El régimen jurídico del Cabildo catedralicio calagurritano hasta la codificación canónica de 1917». Kalakorikos: revista para el estudio, defensa, protección y divulgación del patrimonio histórico, artístico y cultural de Calahorra y su entorno 5: 37-96.
Guijarro González, Susana. 2008: "Jerarquía y redes sociales en la Castilla medieval: la provisión de beneficios eclesiásticos en el cabildo de la catedral de Burgos (1390-1440)». Anuario de Estudios Medievales 38 (1): 271-299. https://doi.org/10.3989/aem.2008. v38.i1.68

Lera Maíllo, José Carlos de. 2014. "Los sellos de jurisdicción de los obispos y cabildo Catedral de Zamora (1182-1255). Estudio sigilográfico y diplomático». En Lugares de Escritura. La catedral, editado por Francisco J. Molina de La Torre, Irene Ruiz Albi y Marta Herrero de la Fuente, 327-339. Valladolid: Universidad.

Linehan, Peter. 1975. La Iglesia española y el papado en el siglo XIII. Salamanca: Universidad Pontificia de Salamanca.

Linehan, Peter. 1981. "A survey of the diocese of Segovia (12461247)». Revista española de Teología 41: 163-206.

Lop Otín, María José. 2003. "Las catedrales y los cabildos catedralicios de la Corona de Castilla durante la Edad Media. Un balance historiográfico». En la España Medieval 26: 371-404.

Luis López, Carmelo. 2004b. «El cabildo de la iglesia Catedral de Ávila a fines de la Edad Media». Espacio, Tiempo y Forma 17: 353-369. https://doi.org/10.5944/etfiii.17.2004.3708

Manzanares Marijuán, Julio. 1993. "Los cabildos de canónigos. Posibilidades y límites de su Estatuto». Memoria ecclesiae IV: 123-147.

Marín Martínez, Tomás. 1991. Paleografía y Diplomática. Madrid: Universidad Nacional de Educación a Distancia.

Marsilla Pascual, Francisco R. 1995-1996. «En torno a la Diplomática episcopal y capitular castellana bajomedieval. Una aproximación». Miscelánea Medieval Murciana XIX-XX: 153-172. https://doi. org/10.6018/j7741

Martín, José Luis y Antonio Linage Conde. 1987. Religión y sociedad medieval. El catecismo de Pedro de Cuéllar (1325). Salamanca: Junta de Castilla y León, Consejería de Cultura y Bienestar Social.

Martín Rodríguez, José Luis. 1987. «El ordenamiento de los capellanes de Segovia». En Homenaje a la memoria del Profesor Emilio Sáez, 495-512. Barcelona: CSIC.

Martín Rodríguez, José Luis. 1989. "Contabilidad interna de los cabildos catedralicios. El "Arte del Contar o Cómpoto" de la Catedral de Segovia». En Homenaje a Marcelo Vigil Pascual: la historia en el contexto de las ciencias humanas y sociales, editado por María José Hidalgo de la Vega, 237-258. Salamanca: Universidad.

Ostos Salcedo, Pilar. 1994. "Documentos y escribanía del cabildo catedralicio de Burgos (siglo XIII)». Espacio, Tiempo y Forma 7: 159-189

Ostos Salcedo, Pilar. 2005. Notarios, documentos notariales y Pedro González de Hoces, veinticuatro de Córdoba. Sevilla: Servicio de Publicaciones Universidad de Sevilla.

Pérez Martín, Antonio. 1999. «El Derecho canónico particular y el Derecho Común Medieval». En Sínodos diocesanos y legislación particular. Estudios históricos en honor al Dr. D. Francisco Cantelar Rodríguez, coordinado por Jaime Justo Fernández, 15-24. Salamanca: Universidad Pontificia de Salamanca.

Pérez-Prendes y Muñoz de Arraco, José Manuel. 1997. Instituciones medievales. Madrid: Síntesis.

Pueyo Colomina, Pilar. 2014. "Documentos episcopales y capitulares (siglos XII-XV)». En Lugares de Escritura. La catedral, editado por Francisco J. Molina de La Torre, Irene Ruiz Albi y Marta Herrero de la Fuente, 131-179. Valladolid: Universidad.

Quintanilla, Mariano. 1955. "Reforma de Estatutos del Cabildo». Estudios Segovianos 7: 195-197.

Ramos Merino, Juan Luis. 2012. Iglesia y notariado en la Castilla bajomedieval. La Catedral de Burgos (1315-1492). Madrid: La Ergástula.

Riesco Terrero, Ángel. 1977. "Constitución Pontificia de Inocencio IV dada a la Iglesia de Salamanca el año 1245. Estudio histórico-diplomático». Ius Canonicum 33: 223-256.

Riesco Terrero, Ángel. 1983. «El sello episcopal hasta el Renacimiento. Valoración jurídico-diplomática y artística del mismo». En Comunicaciones al XV Congreso Internacional de las ciencias genealógica y heráldica, Tomo III, 365-390. Madrid: Instituto Salazar y Castro.

Riesco Terrero, Ángel. 1995. «Diplomática eclesiástica del reino de León hasta 1300 », en El reino de León en la Alta Edad Media VII: 
331-589. León: Centro de Estudios e investigación San Isidoro, Caja España de inversiones, Caja de Ahorros y Monte de Piedad, Archivo Histórico Diocesano.

Rodríguez Díez, José. 2007. «Invitación a una traducción española de corpus iuris canonici». Anuario Jurídico y Económico Escurialense 40: 323-350.

Rodríguez Molina, José. 1975. «Estatutos de la catedral de Jaén: recopilación de 1478». Boletín del Instituto de Estudios Gienenses 85-86: 9-186

Santamaría Lancho, Miguel. 1982. «La organización de la gestión económica del cabildo catedralicio de Segovia. Siglos XIII-XIV». En Ia España medieval 3: 505-540.

Santamaría Lancho, Miguel. 1983. "Una fuente para el estudio de poblamiento y la distribución de la renta agraria en la castilla del
S. XIII: la distribución de los "préstamos"». Hispania Sacra XXXV, 72: 683-702.

Santamaría Lancho, Miguel. 1990. «El cabildo catedralicio de Segovia como aparato de poder en el sistema político urbano durante el siglo XV». Studia historica. Historia medieval 8: 47-78.

Sanz Sancho, Iluminado. 2013. "La catedral, sede del obispo en la Edad Media». Hispania Sacra 65: 371-381. https://doi.org/10.3989/ hs. 2013.025

Vázquez Bertomeu, Mercedes. 1997. «El escritorio capitular compostelano (1460-1481)». Historia. Instituciones. Documentos 24: 497-532.

Vigil Montes, Néstor. 2012. «Una nueva frontera para los estudios sobre los cabildos catedralicios en la Edad Media: el desarrollo de la Diplomática Capitular». Medievalismo 22: 239-254. 